NBER WORKING PAPER SERIES

\title{
UNCOVERED INTEREST PARITY, FORWARD GUIDANCE, AND THE EXCHANGE RATE
}

\author{
Jordi Galí \\ Working Paper 26797 \\ http://www.nber.org/papers/w26797
NATIONAL BUREAU OF ECONOMIC RESEARCH
1050 Massachusetts Avenue
Cambridge, MA 02138
February 2020

I acknowledge financial support from the CERCA Programme/Generalitat de Catalunya and the Severo Ochoa Programme for Centres of Excellence. The views expressed herein are those of the author and do not necessarily reflect the views of the National Bureau of Economic Research.

The author has disclosed a financial relationship of potential relevance for this research. Further information is available online at http://www.nber.org/papers/w26797.ack

NBER working papers are circulated for discussion and comment purposes. They have not been peer-reviewed or been subject to the review by the NBER Board of Directors that accompanies official NBER publications.

(C) 2020 by Jordi Galí. All rights reserved. Short sections of text, not to exceed two paragraphs, may be quoted without explicit permission provided that full credit, including (C) notice, is given to the source. 
Uncovered Interest Parity, Forward Guidance, and the Exchange Rate

Jordi Galí

NBER Working Paper No. 26797

February 2020

JEL No. E43,E58,F41

\title{
ABSTRACT
}

Under uncovered interest parity (UIP), the size of the effect on the real exchange rate of an anticipated change in real interest rate differentials is invariant to the horizon at which the change is expected. Empirical evidence using US, euro area and UK data points to a substantial deviation from that invariance prediction: expectations of interest rate differentials in the near (distant) future are shown to have much larger (smaller) effects on the real exchange rate than is implied by UIP. Some possible explanations are discussed.

\author{
Jordi Galí \\ Centre de Recerca en Economia Internacional (CREI) \\ Ramon Trias Fargas 25 \\ 08005 Barcelona \\ SPAIN \\ and NBER \\ jgali@crei.cat
}


Recent research in monetary economics, using a closed economy New Keynesian model as a reference framework, has emphasized the powerful effects of anticipated changes in interest rates on current output and inflation. ${ }^{1}$ That analysis has drawn a lot of attention given its relevance for the assessment of the effectiveness of forward guidance policies, i.e. the attempt to influence current macroeconomic outcomes in an environement where the zero lower bound (ZLB) is binding by managing expectations about the future path of the policy rate. On the other hand, the implausible size of the macroeconomic effects of anticipated changes in the short term nominal interest rate implied by the standard New Keynesian model and, in particular, its prediction of a positive relation between the horizon of those anticipated changes and the size of their immediate effects, has come to be known as the forward guidance puzzle, and has led many researchers to explore modifications of the assumptions of the standard model in order to get around such implausible implications.

In the present paper I study, both theoretically and empirically, the effects of anticipated interest rate changes in an open economy, focusing on their impact on the exchange rate. When doing so, I take the assumption of uncovered interest parity (UIP, henceforth) and its implications as a theoretical benchmark. This is of particular interest since most open economy models in the literature generally assume UIP. ${ }^{2}$ On the other hand, the fact that UIP has been empirically rejected in the literature does not render the exercise without interest, since it is not clear what are the implications, if any, of the empirical failure of UIP on the effects of anticipated interest rate changes on the exchange rate. ${ }^{3}$ The analysis below allows for a comparison between the predictions of UIP and the empirical evidence with regard to the exchange rate effects of anticipated variations in interest rates.

As discussed below, UIP makes the current exchange rate depend, to a first-order approximation, on the undiscounted sum of expected future interest rate differentials. Importantly, that relation relies only a relatively weak assumption: the existence at each point in time of some deep pocket investors with unconstrained access to both domestic and foreign bonds.

In the first part of the paper I analyze the effects of anticipated interest rate differentials on the exchange rate, under the assumption of constant prices (i.e. ignoring any induced effects on inflation). In that environment, the combination of UIP with the long run neutrality of monetary policy yields a strong implication: the impact on the current exchange rate of an anticipated future adjustment of the nominal rate is invariant to the timing of that adjustment.

Next I revisit the analysis of the effect of anticipated changes in interest rate differentials while allowing for feedback effects on output and prices, using a simple New Keynesian model of a small open economy. I show how, in that environment, the effect of a given anticipated change in the short-term nominal rate on the current exchange rate is larger the longer is the horizon of implementation. A similar prediction applies to the effect on output and inflation. As discussed below, both results are closely connected to the so called forward guidance puzzle uncovered in the recent literature, though that literature has invariably focused on closed economy models

\footnotetext{
${ }^{1}$ See the section below on the background literature for a more detailed discussion and references.

${ }^{2}$ The present paper is not, by any means, the first to study, from a theoretical point of view, the impact of anticipated monetary policies on the exchange rate and other variables. Early work addressing that question includes Wilson (1979), Dornbusch and Fischer (1980) and Mussa (1982). In contrast with the present paper, however, that work, however, made use of not-fully-microfounded models. Most importantly, it did not examine the role played by the horizon of anticipated policies, which is the focus of the present paper.

${ }^{3}$ See, e.g., Bacchetta (2013) and Engel (2014) for a survey of the empirical literature on UIP.
} 
and has thus ignored the real exchange rate channel. ${ }^{4}$

Having analyzed the theoretical implications of UIP on the link between anticipated interest rates and the exchange rate, in the second part of the paper I turn to the data. In particular, I provide some empirical evidence on the exchange rate effects of anticipated future interest rate differentials at different horizons. An open question, which is the focus of the present inquiry, is what the empirical failure of UIP implies with regard to the link between the current real exchange rate and anticipated real interest rate differentials at different horizons. Thus, a key objective of the empirical analysis below is to characterize the potential empirical deviations from the horizon-invariance property implied by the UIP. ${ }^{5}$

Using data for the US, UK and euro area on bilateral real exchange rates and marketbased proxies for anticipated real interest rate differentials at different horizons, I test the horizon-invariance property linking those variables, as implied by the UIP. The evidence points to a strong rejection of that property. Perhaps more interestingly, it suggests a simple characterization of the empirical deviations from horizon-invariance: expectations of interest rate differentials in the near (distant) future appear to have much larger (smaller) effects than predicted under UIP. As far as I know, this particular dimension of the empirical failure of UIP, which I refer to as the forward guidance exchange rate puzzle, has not been uncovered in the existing literature.

The third part of the paper discusses possible interpretations of the empirical findings. In particular, I argue that some of the solutions to the forward guidance puzzle proposed in the closed economy literature are unlikely to apply to the exchange rate channel emphasized in the present paper. Instead I propose a simple behavioral model that is shown to be consistent with the key qualitative findings uncovered in the empirical section.

The remainder of the paper is organized a follows. Section 1 briefly describes the forward guidance puzzle in a closed economy setting. Section 2 discusses the effects of forward guidance on the exchange rate in a partial equilibrium framework. Section 3 revisits that analysis in general equilibrium, using a small open economy New Keynesian model as a reference framework. Section 4 presents the empirical evidence. Section 5 discusses possible interpretations of the evidence. Section 6 summarizes and concludes.

\section{Background: The Forward Guidance Puzzle in the Closed Economy}

In the present section I briefly review the literature on the forward guidance puzzle. The analysis in that literature has been invariably conducted using a closed economy framework.

The effectiveness of forward guidance and its role in the design of the optimal monetary policy under a binding ZLB was analyzed in Eggertsson and Woodford (2003) and Jung et al. (2005), using a standard New Keynesian model. Those papers emphasized the high effectiveness of forward guidance as a stabilizing instrument, as implied by the theory, at least under the maintained assumption of credible commitment.

\footnotetext{
${ }^{4}$ See Carlstrom et al. (2015), Del Negro et al. (2015), and McKay et al. (2016, 2017), among others,

${ }^{5}$ Several recent papers have analyzed the response of the exchange rate to news about future monetary policy, but with a different focus from the one adopted here. See below for discussion and references.
} 
More recently, the contributions of Carlstrom et al. (2015), Del Negro et al. (2015), and McKay et al. $(2016,2017)$, among others, have traced the strong theoretical effectiveness of forward guidance to a "questionable" property of one of the key blocks of the New Keynesian model, the Euler equation, which in its conventional form implies that future interest rates are not "discounted" when determining current consumption. Formally, the standard dynamic IS equation (DIS) of the New Keynesian model can be solved forward and written as: ${ }^{6}$

$$
\widehat{y}_{t}=-\frac{1}{\sigma} \sum_{k=0}^{\infty} \mathbb{E}_{t}\left\{\widehat{r}_{t+k}\right\}
$$

where $y_{t}$ is $(\log )$ output and $r_{t} \equiv i_{t}-\mathbb{E}_{t}\left\{\pi_{t+1}\right\}$ is the real interest rate. The " " symbol denotes deviations of a variable from steady state.

Two predictions of the model stand out. Firstly, the effect on output of a given anticipated change in the real interest rate is invariant to the horizon of implementation of that change. Secondly, when combined with a forward-looking New Keynesian Phillips curve, the previous property implies that the anticipation of a future nominal rate adjustment of a given size and duration is predicted to have a stronger effect on current output and inflation the longer the horizon of implementation. This is so because the implied change in inflation and, hence, in the real rate (with the consequent amplification on the effects on output and inflation) depends on the discounted sum of expected output variations, which is larger the longer is the implementation horizon. The previous two predictions stand at odds with conventional wisdom, and as such they have been (jointly) labeled the forward guidance puzzle.

Several potential "solutions" to the forward guidance puzzle have been proposed in the literature, in the form of modifications of the benchmark model that generate some kind of discounting in the Euler equation. Those modifications include the introduction of finite lives (Del Negro et al. (2015)), incomplete markets (McKay et al. (2016, 2017), Werning (2015), Farhi and Werning (2017)), lack of common knowledge (Angeletos and Lian (2017)), and behavioral discounting (Gabaix (2019)). The proposed solutions typically generate an approximate "discounted" DIS equation of the form

$$
\widehat{y}_{t}=\alpha \mathbb{E}_{t}\left\{\widehat{y}_{t+1}\right\}-\frac{1}{\sigma} \mathbb{E}_{t}\left\{\widehat{r}_{t}\right\}
$$

where $\alpha \in(0,1)$, leading to the forward-looking representation

$$
\widehat{y}_{t}=-\frac{1}{\sigma} \sum_{k=0}^{\infty} \alpha^{k} \mathbb{E}_{t}\left\{\widehat{r}_{t+k}\right\}
$$

which implies that the effect of future interest rate changes on current output is more muted the longer is the horizon of their implementation. Interestingly, and as discussed in section 5 below, several of those solutions would not seem to be relevant to the exchange rate channel emphasized in the present paper.

Next I show that, under the assumption of uncovered interest parity, a phenomenon analogous to the forward guidance puzzle applies to the real exchange rate in an open economy.

\footnotetext{
${ }^{6} \mathrm{I}$ am implicitly assuming the most basic version of the model, with consumption as the only aggregate demand component and $\lim _{T \rightarrow+\infty} \mathbb{E}_{t}\left\{\widehat{y}_{t+T}\right\}=0$. See, e.g., chapter 3 in Galí (2015).
} 


\section{Anticipated Interest Rate Differentials and the Ex- change Rate in Partial Equilibrium}

Consider the asset pricing equations

$$
\begin{gathered}
1=\left(1+i_{t}\right) \mathbb{E}_{t}\left\{\Lambda_{t, t+1}\left(P_{t} / P_{t+1}\right)\right\} \\
1=\left(1+i_{t}^{*}\right) \mathbb{E}_{t}\left\{\Lambda_{t, t+1}\left(\mathcal{E}_{t+1} / \mathcal{E}_{t}\right)\left(P_{t} / P_{t+1}\right)\right\}
\end{gathered}
$$

for all $t$, where $i_{t}$ denotes the yield on a nominally riskless one-period bond denominated in domestic currency purchased in period $t$ (and maturing in period $t+1$ ). $i_{t}^{*}$ is the corresponding yield on an analogous bond denominated in foreign currency. $P_{t}$ is the price index for consumption goods. $\mathcal{E}_{t}$ is the nominal exchange rate, expressed as the price of foreign currency in terms of domestic currency. $\Lambda_{t, t+1}$ is the (real) stochastic discount factor for a (domestic) investor with unconstrained access to the two bonds in period $t$.

Combining (1) and (2) we have

$$
\mathbb{E}_{t}\left\{\Lambda_{t, t+1}\left(P_{t} / P_{t+1}\right)\left[\left(1+i_{t}\right)-\left(1+i_{t}^{*}\right)\left(\mathcal{E}_{t+1} / \mathcal{E}_{t}\right)\right]\right\}=0
$$

In a neighborhood of a perfect foresight steady state, and to a first-order approximation, we can rewrite the previous equation as:

$$
i_{t}=i_{t}^{*}+\mathbb{E}_{t}\left\{\Delta e_{t+1}\right\}
$$

for all $t$, where $e_{t} \equiv \log \mathcal{E}_{t}$. This is the familiar uncovered interest parity (UIP) condition.

Letting $q_{t} \equiv p_{t}^{*}+e_{t}-p_{t}$ denote the (log) real exchange rate, one can write the "real" version of UIP as:

$$
q_{t}=r_{t}^{*}-r_{t}+\mathbb{E}_{t}\left\{q_{t+1}\right\}
$$

where $r_{t} \equiv i_{t}-\mathbb{E}_{t}\left\{\pi_{t+1}\right\}$ is the real interest rate and $\pi_{t} \equiv p_{t}-p_{t-1}$ denotes (CPI) inflation, both referring to the home economy. $r_{t}^{*}$ and with $\pi_{t}^{*}$ are defined analogously for the foreign economy. Assume for simplicity that $\lim _{T \rightarrow+\infty} \mathbb{E}_{t}\left\{q_{T}\right\}$ is well defined and bounded. ${ }^{7}$ In that case, (5) can be solved forward and, after taking the limit as $T \rightarrow \infty$, rewritten as:

$$
q_{t}=\sum_{k=0}^{\infty} \mathbb{E}_{t}\left\{r_{t+k}^{*}-r_{t+k}\right\}+\lim _{T \rightarrow \infty} \mathbb{E}_{t}\left\{q_{T}\right\}
$$

Equation (6) is a straightforward implication of uncovered interest parity, combined with the assumptions of rational expectations and a bounded long run real exchange rate. ${ }^{8}$ It determines

\footnotetext{
${ }^{7}$ Note that the previous assumption is weaker than long-run purchasing power parity (PPP). In the empirical section below, when taking the model to the data, I relax that assumption by allowing for a time trend, possibly resulting from long term productivity growth rate differentials.

${ }^{8}$ Strictly speaking, the assumption of rational expectations can be relaxed in much of the analysis below and replaced instead with subjective expectations $\widetilde{\mathbb{E}}_{t}\{\cdot\}$ as long as they satisfy the law of iterated expectations as well as the transversality condition for the real exchange rate assumed in each case. In that case one can write:

$$
q_{t}=\sum_{k=0}^{\infty} \widetilde{\mathbb{E}}_{t}\left\{r_{t+k}^{*}-r_{t+k}\right\}+\lim _{T \rightarrow \infty} \widetilde{\mathbb{E}}_{t}\left\{q_{T}\right\}
$$

I am grateful to an anonymous referee for the previous observation.

By contrast, in section 6 I discuss an alternative model with a type of nonrational expectations that violate the law of iterated expectations.
} 
the real exchange rate as a function of (i) current and expected real interest rate differentials and (ii) the long run expectation of the real exchange rate. Forward-looking real exchange rate equations similar to (18) have often been used in the empirical exchange rate literature, though not in connection to forward guidance. ${ }^{9}$ For the purposes of the present paper a key property of (6) must be highlighted, namely, the lack of discounting of expected future real interest rate differentials. This property is analogous to the one featured by the dynamic IS equation of the New Keynesian model and which is at the root of the forward guidance puzzle, as discussed above.

In what follows I discuss some of the implications of that property for the real exchange rate and its connection to forward guidance policies, and explore its empirical support.

\subsection{A Forward Guidance Experiment}

Assume that at time $t$ the central bank of a small open economy credibly announces an increase of the nominal interest rate of size $\delta$, starting $T$ periods from now and of duration $D$ (i.e., from period $t+T$ to $t+T+D-1$ ). Interest rates and prices in the rest of the world are assumed to remain unchanged in response to that announcement and its subsequent implementation. Furthermore, assume that the path of domestic prices also remains unchanged (this assumption is relaxed below). Under the assumption of long run neutrality of monetary policy, $\lim _{T \rightarrow \infty} \mathbb{E}_{t}\left\{q_{T}\right\}$ should not change in response to the previous announcement. It follows from (6) that the real exchange rate will vary in response to the announcement by an amount given by

$$
\widehat{q}_{t}=-D \delta
$$

i.e. the exchange rate appreciation at the time of the announcement is proportional to the duration and the size of the announced interest rate increase, but is independent of its planned timing $(T)$. Thus, a $D$-period increase of the real interest rate 10 years from now is predicted to have the same effect on today's real exchange rate as an increase of equal size and duration to be implemented immediately.

Once the interest rate increase is effectively implemented in period $t+T$, the exchange rate depreciates at a constant rate $\delta$ per period, i.e. $\Delta q_{t+T+k}=\delta$ for $k=1,2, . . D$ and stabilizes at its initial level once the intervention concludes, i.e. $q_{t+T+k}=q_{t}$ for $k=D+1, D+2, \ldots$

Figure 1 illustrates the implied path of the interest rate and the exchange rate when an interest rate rise of $1 \%$ (in annual terms) is announced at $t=0$, to be implemented at $T=4$ and lasting for $D=4$ periods.

\footnotetext{
${ }^{9}$ See, e.g., Engel and West (2005) and Engel (2016), among many others.
} 


\section{Anticipated Interest Rate Differentials and the Ex- change Rate in General Equilibrium}

Consider the (log-linearized) equilibrium conditions of a standard small open economy model with Calvo staggered price-setting, law of one price (producer pricing), and complete markets. ${ }^{10}$

$$
\begin{gathered}
\pi_{H, t}=\beta \mathbb{E}_{t}\left\{\pi_{H, t+1}\right\}+\kappa y_{t}-\omega q_{t} \\
y_{t}=(1-v) c_{t}+\vartheta q_{t} \\
c_{t}=\mathbb{E}_{t}\left\{c_{t+1}\right\}-\frac{1}{\sigma}\left(i_{t}-\mathbb{E}_{t}\left\{\pi_{t+1}\right\}\right) \\
c_{t}=\frac{1}{\sigma} q_{t}
\end{gathered}
$$

where $\pi_{H, t} \equiv p_{H, t}-p_{H, t-1}$ denotes domestic inflation, $y_{t}$ is (log) output and $c_{t}$ is (log) consumption. Equation (7) is a New Keynesian Phillips curve for the small open economy. Coefficients $\kappa$ and $\omega$ are defined as $\kappa \equiv \lambda(\sigma+\varphi)$ and $\omega \equiv \frac{\lambda(\sigma \eta-1) v(2-v)}{1-v}$ where $v \in[0,1]$ is an index of openness (equal the share of imported goods in domestic consumption in the steady state), $\sigma>0$ is the (inverse) elasticity of intertemporal substitution, $\eta>0$ is the elasticity of substitution between domestic and foreign goods, and $\lambda \equiv \frac{(1-\theta)(1-\beta \theta)}{\theta}>0$ is inversely related to the Calvo price stickiness parameter $\theta$. (8) is the goods market clearing condition, with $\vartheta \equiv \eta v\left(1+\frac{1}{1-v}\right)>0$. (9) is the consumption Euler equation, with $\pi_{t} \equiv p_{t}-p_{t-1}$ denoting CPI inflation. (10) is the international risk sharing condition, derived under the assumption of complete markets. The above specification of the equilibrium conditions assumes constant output, prices and real interest rates in the rest of the world, normalized to zero for notational ease (i.e. $r_{t}^{*}=y_{t}^{*}=p_{t}^{*}=0$, all $t$ ). Also for simplicity I abstract from any non-policy shocks, with the analysis focusing exclusively on the effects of exogenous monetary policy changes.

Note that (9) and (10) imply the real version of UIP introduced in the previous section: ${ }^{11}$

$$
q_{t}=\mathbb{E}_{t}\left\{q_{t+1}\right\}-\left(i_{t}-\mathbb{E}_{t}\left\{\pi_{t+1}\right\}\right)
$$

Furthermore, under the maintained assumption of full pass through, CPI inflation and domestic inflation are linked by

$$
\begin{aligned}
\pi_{t} & \equiv(1-v) \pi_{H, t}+v \Delta e_{t} \\
& =\pi_{H, t}+\frac{v}{1-v} \Delta q_{t}
\end{aligned}
$$

In order to close the model, a description of monetary policy is required. I assume the simple rule

$$
i_{t}=\phi_{\pi} \pi_{H, t}
$$

\footnotetext{
${ }^{10}$ Detailed derivations of the equilibrium conditions can be found in Galí and Monacelli (2005) and Galí (2015, chapter 8) With little loss of generality I assume an underlying technology that is linear in labor input.

${ }^{11}$ The assumption of complete markets at the international level is sufficient (though not necessary) to derive the uncovered interest parity equation. As discussed in section 2 above that equation can be derived as long as there are some investors each period with unconstrained access to both domestic and foreign one-period bonds.
} 
where $\phi_{\pi}>1$. It can be easily checked that in the absence of exogenous shocks the equilibrium in the above economy is (locally) unique and given by $\pi_{H, t}=y_{t}=q_{t}=i_{t}=0$ for all $t$. $^{12}$

Consider next a forward guidance experiment analogous to the one analyzed in the previous section, but allowing for an endogenous response of inflation to the anticipated change in the interest rate. More specifically, assume that at time 0, the home central bank credibly announces a one-period increase in the nominal interest rate of 0.25 (i.e. one percentage point in annualized terms), to be implemented in period $T$. Furthermore, the central bank commits to keeping the nominal interest rate at its initial level (normalized to zero in the impulse responses) between periods 0 and $T-1$, independently of the evolution of inflation. At time $T+1$ it restores the interest rate rule (13) and, with it, the initial equilibrium.

Figure 2 displays the response of interest rates, the exchange rate, output, and inflation, to the above experiment under three alternative time horizons for implementation: $T=\{1,2,4\}$. The parameters of the model are calibrated as follows: $\beta=0.99, v=0.4, \sigma=\varphi=1, \eta=2$, and $\theta=0.75$. Note that a version of the forward guidance puzzle for the open economy emerges: the longer is the horizon of implementation, the larger is the impact of the announcement on the real and nominal exchange rates as well as on output and inflation. As emphasized by McKay el al. (2016), the reason for the amplification has to do with the fact that inflation depends on current and expected future output, combined with the property that the longer is the implementation of a given interest rise the more persistent the output response. It follows that the longer is the implementation horizon of a given change in the nominal rate the larger will be the response of the real rate -and hence of output and the real exchange rate- between the time of the announcement and that of policy implementation.

Figure 3 illustrates more explicitly the forward guidance puzzle as applies to the nominal and real exchange rates. It displays the percent response of those two variables on impact when a one-period increase in the nominal rate is announced, to be implemented at alternative horizons represented by the horizontal axis. As the Figure makes clear the percent appreciation of the home currency, both in real and nominal terms, increases exponentially with the horizon of implementation. Note also that the appreciation of the nominal exchange rate is substantially larger than that of the real exchange rate, with the gap between the two increasing with the horizon of implementation. That gap, which corresponds to the percent decrease in the CPI in response to the forward guidance announcement, is also increasing in the horizon due to the forward-lookingness of the New Keynesian Phillips curve. The fall in inflation, in turn, leads to a further rise in current and future real interest rates (given an unchanged path for the nominal rate), thus generating an additional appreciation of the real exchange rate.

An alternative perspective on the previous experiment can be obtained by focusing on the determination of the nominal exchange rate. Consider an announcement of an interest rate increase of size $\delta$ and duration $D$, to be implemented $T$ periods ahead. Iterating forward equation (4) we can express the nominal exchange rate at the time of the policy announcement

\footnotetext{
${ }^{12}$ All of the results below carry over unaltered if we assume that the central bank responds to other variables (e.g. output or the exchange rate) in addition to domestic inflation. The reason is twofold: (i) the rule is assumed to be "suspended" between the announcement and the end of the implementation, and (ii) that once the intervention comes to an end (and in the absence of other shocks) the economy immediately jumps to the steady state, independently of the precise form of the rule (as long as equilibrium uniqueness is guaranteed).
} 
as:

$$
\begin{aligned}
e_{t} & =\delta D+\mathbb{E}_{t}\left\{e_{t+T+D}\right\} \\
& =\delta D+\mathbb{E}_{t}\left\{p_{t+T+D}\right\}
\end{aligned}
$$

The first term on the right hand side of (14) captures the dependence of the nominal exchange rate on anticipated changes in nominal interest rate differentials. As discussed in section 2 that effect is a function of the size $(\delta)$ and duration $(D)$ of the anticipated policy intervention, but not of its timing. This captures the partial equilibrium dimension of the forward guidance exchange rate puzzle. The second term, $\mathbb{E}_{t}\left\{p_{t+T+D}\right\}$, which reinforces the effect of the first term, is the result of general equilibrium effects working through (i) the impact on aggregate demand and output of the changes in consumption and the real exchange rate induced by the anticipation of higher future nominal interest rates (given prices), and (ii) their subsequent effects on inflation and the price level, which depend on the duration of the output effects and, hence, on the timing of the policy implementation.

The strength of some the general equilibrium effects at work in the previous simulations is, from an empirical perspective, a controversial subject. This is true, in particular, with regard to the degree of forward-lookingness of inflation, i.e. that variable's sensitivity to expected future output developments. An empirical analysis of the role played by the response of inflation (and, hence, of real interest rates) to anticipated changes in nominal interest rates in the determination of the exchange rate is beyond the scope of the present paper. ${ }^{13}$ Instead, in the remainder of the paper I turn to an empirical exploration of the (partial equilibrium) link between the real exchange rate and anticipated real interest rate differentials, with a focus on the role played by the horizon of anticipated interest rate changes, and having as a benchmark the relationship between those variables implied by the real version of UIP shown in (6).

\section{Anticipated Interest Rate Differentials and the Ex- change Rate: Does the Horizon Matter?}

Next I provide some evidence on the extent to which fluctuations in the real exchange rate can be accounted for by variations in expected interest rate differentials at different horizons. Several recent papers have analyzed the response of the exchange rate to news about future monetary policy, but with a different focus from the one adopted here, i.e. the role of the horizon. Thus, Curcuru et al. (2018) study the differences in the response of the exchange rate and foreign yields to expected short term rates and term premia in the U.S., with the aim of understanding the differences between QE and conventional policies on the exchange rate. Glick and Leduc (2018) estimate the response of the dollar exchange rate against a number of currencies in response to surprises in the policy rate, as well as to changes in short-term and longer-term rates around policy announcements. Both papers point to a substantial increase in the response of the exchange rate to expected interest rates during the period of unconventional monetary

\footnotetext{
${ }^{13}$ See, e.g. Mavroeidis et al. (2014), Rudd and Whelan (2005) and Galí et al. (2005), as well as other contributions to the special issue of the Journal of Monetary Economics (vol. 52, issue 6) on the empirics of the New Keynesian Phillips curve for a discussion of some the issues in that controversy.
} 
policies. but no attempt is made to compare the size of those responses to those implied by the theory, which is the focus of the present inquiry.

The starting point of my empirical analysis is the relation between the real exchange rate and expected future real interest rate differentials implied by the UIP condition. The exact form of the equation to be taken to the data depends on the maintained assumption regarding the long run properties of the real exchange rate. Next I discuss three alternative assumptions regarding those properties.

In the first case considered, purchasing power parity (PPP) is assumed to hold in the long run, so that $\left\{q_{t}\right\}$ is stationary around a constant mean $q$, and $\lim _{T \rightarrow+\infty} \mathbb{E}_{t}\left\{q_{T}\right\}=q$. In that case one can rewrite (6) as

$$
q_{t}=q+\sum_{k=0}^{\infty} \mathbb{E}_{t}\left\{r_{t+k}^{*}-r_{t+k}\right\}
$$

I assume that for a sufficiently long horizon $m$ the following approximation is valid:

$$
\sum_{k=m}^{\infty} \mathbb{E}_{t}\left\{r_{t+k}^{*}-r_{t+k}\right\} \simeq 0
$$

In the empirical implementation below, I assume $m=360$, which corresponds to 30 years. This seems a conservative assumption.

Note that the infinite sum on the right hand side of (15) can be decomposed as the sum of two terms:

$$
q_{t} \simeq q+\underbrace{\sum_{k=0}^{n-1} \mathbb{E}_{t}\left\{r_{t+k}^{*}-r_{t+k}\right\}}_{\equiv D_{t}^{S}(n)}+\underbrace{\sum_{k=n}^{m-1} \mathbb{E}_{t}\left\{r_{t+k}^{*}-r_{t+k}\right\}}_{\equiv D_{t}^{L}(n)}
$$

for any horizon $n \in\{1,2,3, \ldots, m-1\} . D_{t}^{S}(n)$ and $D_{t}^{L}(n)$ capture the anticipated real interest rate differentials at "short" and "long" horizons, respectively, with $n$ being the (arbitrary) horizon that defines the boundary between the two. The empirical strategy pursued below consists of using measures of the (log) real exchange rate, together with empirical proxies for $D_{t}^{S}(n) \equiv \sum_{k=0}^{n-1} \mathbb{E}_{t}\left\{r_{t+k}^{*}-r_{t+k}\right\}$ and $D_{t}^{L}(n) \equiv \sum_{k=n}^{m-1} \mathbb{E}_{t}\left\{r_{t+k}^{*}-r_{t+k}\right\}$, to estimate equation

$$
q_{t}=\alpha+\gamma_{S} D_{t}^{S}(n)+\gamma_{L} D_{t}^{L}(n)
$$

In what follows I refer to (17) as the baseline specification. Note that the joint null of UIP and long run PPP implies $\gamma_{S}=\gamma_{L}=1$, which can be tested. Most interestingly, one may want to examine the size and sign of the estimated deviations from that null, as well as its dependence on the horizon. Before discussing the details of the empirical implementation, I briefly describe two alternative representations of the exchange rate equation that relax the assumption of long run PPP underlying the above specification.

Consider the case of a $(\log )$ real exchange rate that is stationary around a deterministic trend $\alpha+\delta t$. This could be the result of different trend productivity growth rates in the tradable sectors of the two economies considered. Note that in that case $\lim _{T \rightarrow+\infty} \mathbb{E}_{t}\left\{q_{T}\right\}$ is unbounded, so that representation (6) is not well defined (and (15) is invalid). Nevertheless, combining the 
previous assumptions with the arbitrage condition (5) (which remains valid, independently of the long run properties of $q_{t}$ ) one can derive:

$$
\widehat{q}_{t}=\sum_{k=0}^{\infty} \mathbb{E}_{t}\left\{r_{t+k}^{*}-r_{t+k}-\delta\right\}+\lim _{T \rightarrow \infty} \mathbb{E}_{t}\left\{\widehat{q}_{T}\right\}
$$

where $\widehat{q}_{t} \equiv q_{t}-(\alpha+\delta t)$ is the detrended (log) real exchange rate and where $\delta$ becomes the unconditional mean of the real interest rate differential. Under the trend stationarity assumption made here, $\lim _{T \rightarrow+\infty} \mathbb{E}_{t}\left\{\widehat{q}_{T}\right\}=0$. Accordingly, (18) can be rewritten as

$$
q_{t}=\alpha+\delta t+\sum_{k=0}^{\infty} \mathbb{E}_{t}\left\{r_{t+k}^{*}-r_{t+k}-\delta\right\}
$$

Again, I assume that for a sufficiently long horizon $m$ the following approximation holds:

$$
\sum_{k=m}^{\infty} \mathbb{E}_{t}\left\{r_{t+k}^{*}-r_{t+k}-\delta\right\} \simeq 0
$$

i.e., real interest rate differentials are expected to return to their unconditional mean $\delta$ within a horizon of $m$ months. It follows from (19) and (20), that

$$
\begin{aligned}
q_{t} & \simeq \alpha+\delta(t-m)+\sum_{k=0}^{m-1} \mathbb{E}_{t}\left\{r_{t+k}^{*}-r_{t+k}\right\} \\
& \simeq \alpha+\delta(t-m)+D_{t}^{S}(n)+D_{t}^{L}(n)
\end{aligned}
$$

which motivates the estimation of the empirical equation

$$
q_{t}=\alpha_{0}+\delta t+\gamma_{S} D_{t}^{S}(n)+\gamma_{L} D_{t}^{L}(n)
$$

given empirical proxies for $D_{t}^{S}(n)$ and $D_{t}^{L}(n)$. Below I refer to $(22)$ as the time trend specification.

Finally, I consider the case in which the (log) real exchange rate is an $I(1)$ stochastic process, possibly with a deterministic component (i.e., $\Delta q_{t}$ is stationary with mean $\delta$ ). This would be a likely implication of (log) productivity differentials in the tradable sector being themselves $I(1)$ processes. In that case equation (18) remains valid, and can be rewritten under assumption (20) as

$$
q_{t} \simeq \alpha+\delta(t-m)+\sum_{k=0}^{m-1} \mathbb{E}_{t}\left\{r_{t+k}^{*}-r_{t+k}\right\}+\lim _{T \rightarrow \infty} \mathbb{E}_{t}\left\{\widehat{q}_{T}\right\}
$$

Taking first differences, we can write

$$
\Delta q_{t} \simeq \delta+\Delta D_{t}^{S}(n)+\Delta D_{t}^{L}(n)+\varepsilon_{t}
$$

where $\varepsilon_{t} \equiv \lim _{T \rightarrow \infty}\left(\mathbb{E}_{t}-\mathbb{E}_{t-1}\right)\left\{q_{T}\right\}$, i.e. the period $t$ innovation in the expected long-run real exchange rate.

Motivated by the previous considerations, below I also report estimates of the empirical equation

$$
\Delta q_{t}=\delta+\gamma_{S} \Delta D_{t}^{S}(n)+\gamma_{L} \Delta D_{t}^{L}(n)+\varepsilon_{t}
$$


henceforth referred to as the first-difference specification.

As in the baseline representation, the absence of discounting in (6) implies that, ceteris paribus, a change in $D_{t}^{S}(n)$ (given $D_{t}^{L}(n)$ ) should have the same effect on the real exchange rate as a commensurate change in $D_{t}^{L}(n)$ (given $D_{t}^{S}(n)$ ). Furthermore, under UIP that effect should be "one-for-one" in both cases, i.e. $\gamma_{S}=\gamma_{L}=1$, which can be tested. Also, estimates of $\gamma_{S}$ and $\gamma_{L}$ can help characterize the deviations from that null, with $\gamma_{S}$ measuring the sensitivity of the real exchange rate with respect to changes in expected interest rate differentials at shorter run horizons (i.e. over the next $n$ periods), while $\gamma_{L}$ captures the corresponding effect at longer horizons (i.e. beyond $n$ periods).

\subsection{Baseline Empirical Strategy}

In order to estimate (17), (22) and (24) I need to construct empirical counterparts to $D_{t}^{S}(n)$ and $D_{t}^{L}(n)$. I use (zero coupon) yields on government debt at different maturities to approximate expectations of future short term rates. Taking the time unit to be a month (so that $i_{t}, \pi_{t}$ and $r_{t}$ have the interpretation of monthly rates), and letting $i_{t}(n)$ denote the (annualized) zero coupon yield on a government bond maturing in $n$ months, I assume a version of the expectation hypothesis of the form

$$
i_{t}(n) \simeq \frac{12}{n} \sum_{k=0}^{n-1} \mathbb{E}_{t}\left\{i_{t+k}\right\}
$$

with an analogous relation holding for the foreign economy. ${ }^{14}$

Secondly, I use (average) monthly data on inflation swaps at different maturities to approximate inflation expectations at different horizons. ${ }^{15}$ Letting $\pi_{t}^{e}(n)$ denote (annualized) expected inflation between month $t$ and month $t+n$, one can rewrite (25) as

$$
\sum_{k=0}^{n-1} \mathbb{E}_{t}\left\{r_{t+k}\right\}=\frac{n}{12}\left[\left(i_{t}(n)-\pi_{t}^{e}(n)\right]\right.
$$

with an analogous relation holding for the foreign economy.

The previous relation is used below in order to compute, for each month, an empirical counterpart to the sum of expected real rate differentials over the subsequent $n$ months, given data on government bond yields, inflation expectations for the home and foreign economies. More specifically,

$$
\begin{aligned}
D_{t}^{S}(n) & \equiv \sum_{k=0}^{n-1} \mathbb{E}_{t}\left\{r_{t+k}^{*}-r_{t+k}\right\} \\
& =\frac{n}{12}\left[\left(i_{t}^{*}(n)-\pi_{t}^{e *}(n)\right)-\left(i_{t}(n)-\pi_{t}^{e}(n)\right)\right]
\end{aligned}
$$

Finally, and given the assumptions above, one can obtain a measure of $D_{t}^{L}(n)$, the antici-

\footnotetext{
${ }^{14}$ The results discussed in this section carry over in a straightforward way to the case of a constant term premium. In the robustness section below I allow for a time-varying term premium.

${ }^{15}$ I thank Philippe Andrade and Hervé le Bihan for helping me obtain the inflation expectations data. Below I pursue an alternative approach to approximate inflation expectations.
} 
pated real interest rate differentials at "long" horizons, using

$$
\begin{aligned}
D_{t}^{L}(n) & \equiv \sum_{k=n}^{m-1} \mathbb{E}_{t}\left\{r_{t+k}^{*}-r_{t+k}\right\} \\
& =D_{t}^{S}(m)-D_{t}^{S}(n)
\end{aligned}
$$

and given measures of $D_{t}^{S}(m)$ and $D_{t}^{S}(n)$ constructed using $(27) .{ }^{16}$

\subsection{Data}

I use monthly data on (zero coupon) yields for German, US and UK government bonds with 1,2,5,10 and 30 year maturities. Monthly measures of expected inflation over the same five horizons are based on the corresponding inflation swap contracts. I construct monthly time series for the real exchange rate, using data on the euro-dollar, pound-dollar, and poundeuro nominal exchange rates, and the CPI indexes for the US, euro area and UK economies. Constraints on data availability on inflation swap contracts force me to start the sample period in 2004:8. As noted above I assume a "long horizon" $m$ equal to 360 months (corresponding to a 30 year horizon). I construct time series for $D_{t}^{S}(n)$ and $D_{t}^{L}(n)$ using the relations $(27)$ and (28) above, for $n=12,24,60,120,360$.

\subsection{Empirical Findings}

Tables $1 \mathrm{~A}-1 \mathrm{C}$ report the main empirical findings of the paper, based on data for the US and the euro area (Table 1A), US and the UK (Table 1B) and euro area and UK (Table 1C). Each table contains three panels, displaying respectively the OLS estimates of $\gamma_{S}$ and $\gamma_{L}$ for each of the three specifications introduced above. In each case, estimates are reported for horizons $n \in\{12,24,60,120\}$. In the case of $n=360 \mathrm{I}$ only report the estimate for $\gamma_{S}$ since $D_{t}^{L}(360) \simeq 0$ under the assumptions made. The sample period is 2004:8-2018:12. Standard errors, reported in brackets, were computed using the Newey-West adjustment for serial correlation, with a 12 lag window.

I start by describing the evidence for the euro-dollar exchange rate, based on US and euro area data, and reported in Table 1A. Note that most of the estimated coefficients are positive and highly significant. Thus, the evidence confirms the link between the real exchange rate and current and expected real interest rate differentials, with the sign of the relation consistent with the theory. The associated $R^{2}$ is very high for the baseline and time trend specifications, regardless of the horizon; perhaps not surprisingly it is lower for the first difference specification, given the amount of exchange rate "noise" at high frequencies. In particular the reasonably good fit of the equation linking the real exchange rate to the sum of anticipated real interest rate differentials at all horizons (i.e up to 30 years ahead), shown in the last row of each panel,

\footnotetext{
${ }^{16}$ Again, as noted in footnote (8), the analysis would go through if bond yields and swap contracts reflect investors' subjective (i.e. nonrational) expectations of future short term rates and inflation rates, as long as those expectarions satisfy the law of iterated expectations. In that case we would have $D_{t}^{S}(n) \equiv \sum_{k=0}^{n-1} \widetilde{\mathbb{E}}_{t}\left\{r_{t+k}^{*}-r_{t+k}\right\}$ and $D_{t}^{L}(n) \equiv \sum_{k=n}^{m} \widetilde{\mathbb{E}}_{t}\left\{r_{t+k}^{*}-r_{t+k}\right\}$, with the empirical analysis below unchanged.
} 
provides clear evidence against any notion of "decoupling" between the exchange rate and anticipated interest rates, and would seem to be consistent with a literature that uncovers a much weaker rejection of UIP at long horizons. ${ }^{17}$

On the other hand, the null $\gamma_{S}=\gamma_{L}=1$ is easily rejected for all specifications ( $p$ values are extremely low and not reported). Most interestingly, the estimates for $\gamma_{S}$ are in all cases much larger than those of $\gamma_{L}$, by an order of magnitude. In words: changes in expected real interest rate differentials in the near future are associated with much larger variations in the real exchange rate than commensurate changes anticipated to take place in the more distant future. Furthermore, and consistent with that interpretation, a look at the pattern of $\gamma_{S}$ estimates across different values of $n$ suggests that the exchange rate elasticity with respect to expected interest rate differentials diminishes monotonically with the horizon. In particular, for all the specifications, $\gamma_{S}$ is larger than one -the value implied by the UIP theoretical benchmark- for horizons up to two years. In general the point estimates for both $\gamma_{S}$ and $\gamma_{L}$ are smaller in the first difference specification. For the baseline and time trend specifications the $\gamma_{S}$ estimate is also significantly above one for $n=60$, corresponding to a horizon of five years, and for shorter horizons it is more than twice the size implied by the benchmark model. On the other hand, the elasticity of the real exchange rate with respect to expected real interest rate differentials at long horizons, given by $\gamma_{L}$, is systematically less than one, and significantly so. The previous findings imply that, relative to the UIP benchmark, exchange rates tend to overreact to changes in expected interest rate differentials at short horizons, while they tend to underreact to similar expected changes at long horizons. I refer to this apparent disconnect between theory and empirics as the forward guidance exchange rate puzzle. ${ }^{18}$

The evidence for the pound-dollar exchange rate, based on US and UK data, is summarized in Table 1B. that evidence is qualitatively very similar to that for the euro-dollar exchange rate. In particular, the estimates for $\gamma_{S}$ systematically decrease with the horizon, and are significantly larger than one at short horizons. Similarly, the estimates for $\gamma_{L}$ are smaller than one uniformly and, with one exception, insignificantly different from zero at long horizons in some cases (with some point estimates being slightly negative).

Table $1 \mathrm{C}$ reports the evidence for the pound-euro exchange rate. Again, most of the main qualitative findings emphasized above also obtain when data for the UK and the euro area are used. The only discrepancy in that regard are given by the estimates corresponding to the first difference specification, which are mostly insignificant in the case of the pound-euro evidence.

\subsection{Robustness}

Next I examine the robustness of the above empirical findings to two alternative empirical strategies. The first one allows for time-varying term premia. The second one uses an alternative proxy for inflation expectations.

\footnotetext{
${ }^{17}$ See, e.g., Chinn and Meredith (2004), Chinn (2006), and Chinn and Quayyum (2013) for a discussion of long horizon UIP.

${ }^{18}$ Note that this interpretation of the evidence is valid even if expectations are not rational, as long as they satisfy the law of iterated expectations.
} 


\subsubsection{Time-Varying Term Premia}

I relax the expectations hypothesis maintained above by allowing for a time-varying term premium. Thus, for a (zero coupon) bond maturing in $n$ months I assume

$$
i_{t}(n)=\frac{12}{n} \sum_{k=0}^{n-1} \mathbb{E}_{t}\left\{i_{t+k}\right\}+v_{t}(n)
$$

where $v_{t}(n)$ denotes the corresponding (annualized) term premium. An analogous relation holds for the foreign economy.

Below I use the estimates of the term premium at different maturities in Adrian et al. (2019) to measure $v_{t}(n)$, obtained using the approach developed in Adrian et al. (2013). ${ }^{19}$ Given an estimate for $v_{t}(n)$ I construct a measure of the expected real rate differentials at "short" horizons, $D_{t}^{S}(n)$, as follows:

$$
\begin{aligned}
D_{t}^{S}(n) & \equiv \sum_{k=0}^{n-1} \mathbb{E}_{t}\left\{r_{t+k}^{*}-r_{t+k}\right\} \\
& =\frac{n}{12}\left[\left(i_{t}^{*}(n)-\pi_{t}^{e *}(n)-v_{t}^{*}(n)\right)-\left(i_{t}(n)-\pi_{t}^{e}(n)-v_{t}(n)\right)\right]
\end{aligned}
$$

The construction of measures of expected real rate differentials at "long" horizons, $D_{t}^{L}(n)$, as well as the rest of the empirical implementation proceeds as above. Tables $2 \mathrm{~A}-2 \mathrm{C}$ report the corresponding estimates using data for the US and the euro area (Table 2A), US and the UK (Table 2B) and euro area and UK (Table 2C). While the size and significance of the estimates for $\gamma_{S}$ are generally weakened relative to the baseline estimates above (especially for the europound), the UIP-implies null of $\gamma_{S}=\gamma_{L}=1$ is rejected in all cases at conventional significance levels. For all specifications the estimated response of the real exchange rate to interest rate differentials at "long" horizons is well below one, and often insignificant. By contrast, for most specifications, the corresponding response to interest rate differentials at "short" horizons, $\gamma_{S}$, is estimated to be "more than one-for-one," although it is sometimes less precisely estimated than in the baseline evidence above. All in all, it seems safe to conclude that the main findings above are not due to the biases generated by time-varying term premia.

\subsubsection{Alternative Proxy for Inflation Expectations}

In the present subsection I report the results from an alternative specification based on a "statistical" proxy for expected inflation. Assume, for simplicity, a stationary real exchange rate (and, hence, a zero unconditional mean for the real interest rate differential). ${ }^{20}$ Under the assumption that $\sum_{k=m}^{\infty} \mathbb{E}_{t}\left\{r_{t+k}^{*}-r_{t+k}\right\} \simeq 0$ for sufficiently large $m$, one can write the exchange rate equation (6) as follows:

\footnotetext{
${ }^{19}$ Their method uses the first five estimated principal components of Treasury yields as pricing factors. Lags and innovations of those pricing factors are used to estimate risk exposures of different bond returns, with a cross-sectional regression of exposures to lagged factors on exposires to innovations shown to identify the parameters to determine the market price of risk. See Adrian et al. (2013) for a detailed description of their approach. That approach has been often adopted in empirical applications. See, e.g., Curcuru et al. (2018).

${ }^{20}$ The analysis can be easily generalized to the case of a non-zero mean for real interest rate differentials.
} 


$$
q_{t} \simeq q+\sum_{k=0}^{m-1} \mathbb{E}_{t}\left\{i_{t+k}^{*}-i_{t+k}-\delta_{\pi}\right\}-\sum_{k=0}^{m-1} \mathbb{E}_{t}\left\{\pi_{t+1+k}^{*}-\pi_{t+1+k}-\delta_{\pi}\right\}
$$

where $\delta_{\pi}$ is the unconditional mean of the inflation and nominal interest rate differentials. Here I assume that inflation differentials can be approximated by an $A R(1)$ process, with autoregressive coefficient $\rho_{\pi}$. Thus, we can rewrite the real exchange rate equation (30) as follows:

$$
q_{t} \simeq q+[\psi(n)-m] \delta_{\pi}+\sum_{k=0}^{m-1} \mathbb{E}_{t}\left\{i_{t+k}^{*}-i_{t+k}\right\}-\psi(n)\left(\pi_{t}^{*}-\pi_{t}\right)
$$

where $\psi(n) \equiv \frac{\rho_{\pi}-\rho_{\pi}^{m}}{1-\rho_{\pi}}$. Let $I_{t}^{S}(n) \equiv \sum_{k=0}^{n-1} \mathbb{E}_{t}\left\{i_{t+k}^{*}-i_{t+k}\right\}$ and $I_{t}^{L}(n) \equiv \sum_{k=0}^{m-1} \mathbb{E}_{t}\left\{i_{t+k}^{*}-i_{t+k}\right\}$ denote, respectively, the sum of expected nominal interest rate differentials at short and long horizons. I estimate the regression equation

$$
q_{t}=\alpha+\gamma_{S} I_{t}^{S}(n)+\gamma_{L} I_{t}^{L}(n)+\lambda\left(\pi_{t}^{*}-\pi_{t}\right)
$$

for horizons $n \in\{12,24,60,120\}$, using $\frac{n}{12}\left[\left(i_{t}^{*}(n)-i_{t}(n)\right]\right.$ as an empirical proxy for $I_{t}^{S}(n)$, and the fact that $I_{t}^{L}(n)=I_{t}^{S}(m)-I_{t}^{S}(n)$, with $m=360$. Again, I take the UIP null of $\gamma_{S}=\gamma_{L}=1$ as a benchmark relative to which one may assess the response of the exchange rate to anticipated interest rate differentials. Similarly to the baseline model above, I also estimate a version of (31) allowing for a time trend as well as a specification in first differences. As above I focus on the estimates for $\gamma_{S}$ and $\gamma_{L}$, which are reported in Tables 3A-3C, respectively based on data for the US and euro area, US and UK, and euro area and UK. Note that for all country pairs, the main patterns uncovered in our baseline empirical model also emerge here. In particular, the exchange rate response to expected interest rate differentials at short horizons is much stronger than its counterpart at long horizons (i.e. $\gamma_{S} \gg \gamma_{L}$ ). More specifically, there is strong evidence of excess sensitivity of the exchange rate to changes in nominal interest rate differentials expected in the near future (i.e. $\gamma_{S} \gg 1$ for low $n$ ), but excess smoothness with respect to corresponding changes at longer horizons (i.e. $\gamma_{L} \ll 1$ ).

\section{Discussion and Possible Explanations}

The empirical analysis of the dynamic relation between the exchange rate and anticipated interest rate differentials described in the previous section has taken as a benchmark the UIP condition (5). It is that UIP condition which, combined with rational expectations and alternative assumptions on the long run properties of the real exchange rate, yields the forward-looking "undiscounted" exchange rate representations (16), (21) and (23) that have been taken to the data in the previous section.

From that perspective, the empirical rejection of the undiscounted exchange rate equations reported above can be seen as pointing to an additional implication of UIP which is shown to be at odds with the evidence. ${ }^{21}$ The question remains as to what alternative model can account for the relationship between the exchange rate and expected interest rate differentials

\footnotetext{
${ }^{21}$ See, e.g. Bacchetta (2013) and Engel (2014) for surveys of the empirical literature on UIP.
} 
at different horizons uncovered in the previous section, and which I have labeled the forward guidance exchange rate puzzle.

Let $\zeta_{t} \equiv r_{t}^{*}-r_{t}+\mathbb{E}_{t}\left\{\Delta q_{t+1}\right\}$ define the deviation from the UIP condition. Under rational expectations, $\zeta_{t}$ has a natural interpretation as the (foreign exchange) risk premium, i.e. the expected excess return on foreign bonds relative to home bonds required by investors. We can generalize (5) and write it as:

$$
q_{t}=r_{t}^{*}-r_{t}+\mathbb{E}_{t}\left\{q_{t+1}\right\}-\zeta_{t}
$$

Note that (32) holds by construction, since it involves no more than the definition of the risk premium. With little loss of generality, assume that the risk premium $\left\{\zeta_{t}\right\}$ is stationary with a zero unconditional mean. ${ }^{22}$ Assuming a stationary real exchange rate for expositional convenience, we can iterate (32) forward to obtain:

$$
q_{t} \simeq q+D_{t}^{S}(n)+D_{t}^{L}(n)-v_{t}
$$

where $v_{t} \equiv \sum_{k=0}^{\infty} \mathbb{E}_{t}\left\{\zeta_{t+k}\right\}$ is the expected cumulative risk premium. Under the null hypothesis that the risk premium is orthogonal to interest rate differentials at all leads and lags, OLS estimates of $\gamma_{S}$ and $\gamma_{L}$ in (17) should be consistent and thus converge asymptotically to one, even though UIP (in a strict sense) no longer holds due the presence of a time-varying risk premium. The evidence reported above is thus in conflict with the hypothesis of uncorrelated fluctuations in the risk premium (at least when the latter is defined under the assumption of rational expectations).$^{23}$

When thinking about possible explanations for the above evidence it is worth noting that some of the solutions to the closed economy forward guidance puzzle found in the literature are unlikely to apply to the case at hand. Those solutions involve a "downward adjustment" in the elasticity of individual expected future marginal utility with respect to aggregate consumption as a consequence of a variety of assumptions, including the risk of death (Del Negro et al. (2015)) or the risk of lower future consumption (relative to aggregate consumption) in the presence of idiosyncratic shocks, incomplete markets, and borrowing constraints (e.g. McKay et al. (2016)). Angeletos and Lian (2017), on the other hand, consider an economy where, in the absence of common knowledge, each individual consumer "discounts" the response of others to anticipated changes in interest rates. The resulting mitigation in the anticipated response of aggregate consumption and output leads to a dampened response of individual consumption. ${ }^{24}$

In the previous models, aggregate consumption often becomes less sensitive to interest rates, especially future ones. ${ }^{25}$ In some simple examples of those models (e.g. McKay et al. (2017),

\footnotetext{
${ }^{22}$ The generalization to a risk premium with a nonzero unconditional mean is straightforward.

${ }^{23}$ This is also the case for other empirical rejections of UIP found in the literature, including the rejection of $H_{0}: \gamma=1$ in the regression equation $\Delta e_{t+1}=\alpha+\gamma\left(i_{t}-i_{t}^{*}\right)+\zeta_{t}$.

${ }^{24}$ See also Farhi and Werning (2019), who study a model with incomplete markets and bounded rationality, emphasizing the interaction between the two factors in accounting for the mitigated effects of monetary policy at long horizons.

${ }^{25}$ As argued by Werning (2015) that "discounting" of future interest rates is not a general consequence of the presence of incomplete markets, depending critically on the cyclicality of household income risk in response to changes in interest rates.
} 
the aggregate consumption Euler equation can be written, up to a first order approximation, as

$$
c_{t}=\alpha \mathbb{E}_{t}\left\{c_{t+1}\right\}-\frac{1}{\sigma} \mathbb{E}_{t}\left\{r_{t}\right\}
$$

where $\alpha \in(0,1)$, thus implying the geometric discounting of anticipated future interest rates.

The interest parity condition (5), on the other hand, should hold (to a first order approximation) independently of the properties of the discount factor, the presence of incomplete markets, or the possibility of no common knowledge, as long as there are some deep pocket investors with rational expectations and costless access to both home and foreign riskless bonds. In other words, (5) is little more than an "arbitrage" equation between two assets which should hold, conditional on the anticipated path of real interest rate differentials, independently of other factors determining the economy's aggregate behavior.

Next I briefly discuss other candidate explanations for the forward guidance exchange rate puzzle, starting with some that maintain the assumption of rational expectations.

As emphasized in the literature, a possible reason for the observed deviations from UIP is that (5) may be an inadequate approximation to the arbitrage condition (3), since it ignores potentially important higher-order terms that may account for the joint comovement of the risk premium and interest rate differentials needed to explain the empirical findings above. I view as a challenge for future research to come up with a model of risk premium determination which can reconcile the frictionless arbitrage condition (3) with the evidence reported in the previous section, while preserving the assumption of rational expectations.

In a recent paper, Bacchetta and van Wincoop (2019) analyze a two-country overlapping generations model with convex portfolio adjustment costs. ${ }^{26}$ The presence of those costs poses a limit to arbitrage and leads to the emergence of a time-varying risk premium in response to changes in interest rate differentials. In particular, the authors show that in the equilibrium of their model the following representation for the (log) real exchange rate holds:

$$
q_{t}=\varphi q_{t-1}+\sum_{k=0}^{\infty} \alpha^{k} \mathbb{E}_{t}\left\{r_{t+k}^{*}-r_{t+k}\right\}
$$

where coefficients $\alpha \in[0,1)$ and $\varphi \in[0,1)$ are, respectively, increasing and decreasing in the parameter that indexes the importance of portfolio adjustment costs. The fact that the dependence on anticipated interest rate differentials declines with the horizon leads the authors to suggest that their model may potentially account for the forward guidance exchange rate puzzle uncovered in the present paper. While (33) seems consistent with the evidence of a dampened effect of anticipated interest rate changes at long horizons, it is far from clear how that model may generate the overreaction to anticipated interest rate changes at short horizons uncovered above.

\footnotetext{
${ }^{26}$ In addition to the forward guidance exchange rate puzzle, the authors show that their model can potentially account for other five exchange rate puzzles: delayed overshooting, forward discount puzzle, predictability reversal, the Engel puzzle, and the Lustig-Stathopoulos-Verdelhan puzzle.
} 


\subsection{A Simple Behavioral Model}

Alternatively, one may seek to account for the forward guidance exchange rate puzzle by allowing for some deviation from rational expectations. Consider the alternative UIP condition:

$$
q_{t}=r_{t}^{*}-r_{t}+\widetilde{\mathbb{E}}_{t}\left\{q_{t+1}\right\}
$$

where $\widetilde{\mathbb{E}}_{t}\{\cdot\}$ denotes the subjective expectations operator. As in the behavioral model of Gabaix (2019), I assume that subjective expectations involve some discounting relative to rational expectations, in particular, when applied to future deviations of the real exchange rate from its long run value, i.e. $\widetilde{\mathbb{E}}_{t}\left\{\widehat{q}_{t+1}\right\}=\alpha \mathbb{E}_{t}\left\{\widehat{q}_{t+1}\right\}$, for $\alpha \in[0,1)$. Under the assumption of long run PPP (for convenience), we can thus rewrite

$$
\widehat{q}_{t}=\sum_{k=0}^{\infty} \alpha^{k} \mathbb{E}_{t}\left\{r_{t+k}^{*}-r_{t+k}\right\}
$$

with anticipated changes in real interest rate differentials in the distant future predicted to have a more muted effect on the real exchange rate than those anticipated over a shorter horizon. ${ }^{27}$ Note, however, that such an assumption would not be able to account for the seeming overreaction of the real exchange rate to anticipated changes in interest rate differentials in the near future, as implied by the estimates reported above. That shortcoming could in principle be overcome by a simple variation on the previous behavioral model, which I briefly describe next. Suppose that the relevant no arbitrage condition is given instead by

$$
r_{t}=r_{t}^{*}+\varkappa \widetilde{\mathbb{E}}_{t}\left\{\Delta q_{t+1}\right\}
$$

where $\varkappa \geq 0$ is the weight that investors attach to exchange rate changes when forming expectations about returns on the foreign asset. Note that $\varkappa=1$ under UIP, as consistent with rational behavior. Under the assumption made above that $\widetilde{\mathbb{E}}_{t}\left\{\widehat{q}_{t+1}\right\}=\alpha \mathbb{E}_{t}\left\{\widehat{q}_{t+1}\right\}$ with $\alpha \in[0,1)$, we have

$$
\widehat{q}_{t}=\frac{1}{\varkappa} \sum_{k=0}^{\infty} \alpha^{k} \mathbb{E}_{t}\left\{r_{t+k}^{*}-r_{t+k}\right\}
$$

Thus, if $\varkappa$ is smaller than one, i.e. if investors downweigh the contribution of exchange rate changes when forming expectations about future returns on foreign assets, (35) can potentially account for the evidence reported above: relative to the UIP benchmark, exchange rates will tend to overreact to changes in (rationally) expected interest rate differentials at short horizons, while they will tend to underreact to similar expected changes at long horizons. To illustrate that point, assume that the real interest rate differential follows the stationary process:

$$
r_{t}^{*}-r_{t}=u_{t}+v_{t}
$$

\footnotetext{
${ }^{27}$ Note that the type of subjective expectations assumed here do not satisfy the law of iterated expectations, thus preventing one from writing an exchange rate equation of the form$$
\widehat{q}_{t}=\sum_{k=0}^{\infty} \widetilde{\mathbb{E}}_{t}\left\{r_{t+k}^{*}-r_{t+k}\right\}
$$

which, as discussed earlier, would have implied invariance to the nature of expectations if the latter applied to all markets. For simplicity, the analysis of the example below proceeds as if only exchange rate expectations deviate from the rational expectations benchmark (i.e. I assume that bond yields and inflation swap contracts reflect rational expectations of future short term interest rates and inflation rates).
} 
where $\left\{u_{t}\right\}$ and $\left\{v_{t}\right\}$ are $A R(1)$ processes with autoregressive coefficients $\rho_{u}$ and $\rho_{v}$, respectively, with $0<\rho_{v}<\rho_{u}<1 .^{28}$ In that case (35) implies

$$
q_{t}=\frac{1}{\varkappa\left(1-\alpha \rho_{u}\right)} u_{t}+\frac{1}{\varkappa\left(1-\alpha \rho_{v}\right)} v_{t}
$$

In addition, we have

$$
\begin{aligned}
D_{t}^{S}(n) & \equiv \sum_{k=0}^{n-1} \mathbb{E}_{t}\left\{r_{t+k}^{*}-r_{t+k}\right\} \\
& =\frac{1-\rho_{u}^{n}}{1-\rho_{u}} u_{t}+\frac{1-\rho_{v}^{n}}{1-\rho_{v}} v_{t}
\end{aligned}
$$

and

$$
\begin{aligned}
D_{t}^{L}(n) & \equiv \sum_{k=n}^{\infty} \mathbb{E}_{t}\left\{r_{t+k}^{*}-r_{t+k}\right\} \\
& =\frac{\rho_{u}^{n}}{1-\rho_{u}} u_{t}+\frac{\rho_{v}^{n}}{1-\rho_{v}} v_{t}
\end{aligned}
$$

It can easily checked that, for any given horizon $n, q_{t}=\gamma_{S}(n) D_{t}^{S}(n)+\gamma_{L}(n) D_{t}^{L}(n)$ holds exactly, where $\gamma_{S}(n)$ and $\gamma_{L}(n)$ satisfy the linear relation:

$$
\left[\begin{array}{cc}
1-\rho_{u}^{n} & \rho_{u}^{n} \\
1-\rho_{v}^{n} & \rho_{v}^{n}
\end{array}\right]\left[\begin{array}{c}
\gamma_{S}(n) \\
\gamma_{L}(n)
\end{array}\right]=\left[\begin{array}{c}
\frac{1-\rho_{u}}{\varkappa\left(1-\alpha \rho_{u}\right)} \\
\frac{1-\rho_{v}}{\varkappa\left(1-\alpha \rho_{v}\right)}
\end{array}\right]
$$

Given $\left(\rho_{u}, \rho_{v}, \alpha, \varkappa\right)$ one can use (36) to determine the implied values of $\gamma_{S}(n)$ and $\gamma_{L}(n)$ for any horizon $n$. Table 4 reports the values for $\gamma_{S}(n)$ and $\gamma_{L}(n)$ at horizons $n=12,24,60,120$ based on the settings for $\left(\rho_{u}, \rho_{v}, \alpha, \varkappa\right)$ that minimize the distance function

$$
\sum_{n=12,24,60,120} f(n)
$$

where $f(n) \equiv\left[\left(1-\rho_{u}^{n}\right) \widehat{\gamma}_{S}(n)+\rho_{u}^{n} \widehat{\gamma}_{L}(n)-\frac{1-\rho_{u}}{\varkappa\left(1-\alpha \rho_{u}\right)}\right]^{2}+\left[\left(1-\rho_{v}^{n}\right) \widehat{\gamma}_{S}(n)+\rho_{v}^{n} \widehat{\gamma}_{L}(n)-\frac{1-\rho_{v}}{\varkappa\left(1-\alpha \rho_{v}\right)}\right]^{2}$, where $\widehat{\gamma}_{S}(n)$ and $\widehat{\gamma}_{L}(n)$ the OLS estimates for $\widehat{\gamma}_{S}$ and $\widehat{\gamma}_{L}$ corresponding to each horizon considered, and drawn from Tables 1A-1C corresponding to US-Euro Area, US-UK and Euro Area-UK evidence, respectively, with the corresponding settings for $\left(\rho_{u}, \rho_{v}, \alpha, \varkappa\right)$ given by $(0.99,0.98,0.99,0.73)$, $(0.99,0.98,0.98,0.43)$ and $(0.99,0.98,0.99,0.60)$. As the Table makes clear, the simple behavioral model is capable of accounting for the qualitative patterns observed in the empirical evidence reported above. In particular, the calibrations considered generate values for coefficient $\gamma_{S}$ that systematically decrease with the horizon, and are substantially larger than one at short horizons, while the implied values for $\gamma_{L}$ are smaller than one uniformly (and smaller than their $\gamma_{S}$ counterparts). It is worth noting that this is attained with a relatively small departure from the rational model, with the subjective discount factor $\alpha$ being very close to one, and the chosen settings for $\varkappa$ implying a downweighing of anticipated exchange rate movements of between $23 \%$ and $67 \%$ in investors' computation of the expected return on foreign assets.

\footnotetext{
${ }^{28} \mathrm{~A}$ two-component structure is assumed in order to avoid perfect colinearity between $D_{t}^{S}(n)$ and $D_{t}^{L}(n)$.
} 


\section{Concluding Comments}

The present paper has explored the the theory and evidence on the exchange rate effects of anticipated changes in interest rate differentials. Under the theoretical benchmark of uncovered interest rate parity (UIP) the current exchange rate is shown to be determined by current and expected future interest rate differentials, undiscounted. Accordingly, in partial equilibrium (i.e. ignoring the feedback effects on inflation) the effect on the current exchange rate of a given anticipated change in the interest rate does not decline with the horizon of its implementation. Using a New Keynesian model of a small open economy as a reference framework, I show that when prices are allowed to respond endogenously, the size of the effect of anticipated changes in the nominal rate on the current exchange rate, as well as on output and inflation, is larger the longer is the horizon of implementation of the announced policies.

Using data on real exchange rates and market-based forecasts of real interest rate differentials for the US, UK and the euro area, I have provided evidence that conflicts with the prediction of undiscounted effects of anticipated real interest rate differentials. In particular, my findings suggest that expectations of interest rate differentials in the near (distant) future appear to have much larger (smaller) effects than is implied by the theory, an observation which I refer to as the forward guidance exchange rate puzzle. Finally, I have discussed the merits of several hypotheses as explanations to that puzzle. 


\section{REFERENCES}

Adrian, Tobias, Richard K. Crump, and Emanuel Moench (2013): "Pricing the Term Structure with Linear Regressions," Journal of Financial Economics, 110, 110-138.

Adrian, Tobias, Richard K. Crump, Benson Durham and Emanuel Moench (2019): "Sovereign Yield Comovements," work in progress.

Angeletos, George-Marios and Chen Lian (2017): "Forward Guidance without Common Knowledge," American Economic Review 108(9), 2477-2512.

Bacchetta, Philippe (2013): "Explaining Deviations from Uncovered Interest Rate Parity," in G. Caprio (ed.), Handbook of Safeguarding Global Financial Stability: Political, Social, Cultural, and Economic Theories and Models, Vol. 2, 209-212.

Bacchetta, Philippe and Eric van Wincoop (2018): "Exchange Rates, Interest Rates and Gradual Portfolio Adjustment," work in progress.

Carlstrom, Charles T., Timothy S. Fuerst, Matthias Paustian (2015): "Inflation and Output in New Keynesian Models with a Transient Interest Rate Peg," Journal of Monetary Economics $76,230-243$

Chinn, Menzie D. (2006): "The (Partial) Rehabilitation of Interest Parity in the Floating Era: Longer Horizons, Alternative Expectations, and Emerging Markets," Journal of International Money and Finance 25, 7-21.

Chinn, Menzie D. and Guy Meredith (2004): "Monetary Policy and Long-Horizon Uncovered Interest Rate Parity," IMF Staff Papers 51(3), 409-430.

Chinn, Menzie D. and Saad Quayyum (2013): "Long Horizon Uncovered Interest Parity Revisited," unpublished manuscript.

Cook, David and Michael Devereux (2013): "Exchange Rate Flexibility under the Zero Lower Bound: The Need for Forward Guidance," mimeo.

Curcuru, Stephanie E., Steven B. Kamin, Canlin Li, and Marius Rodriguez (2018): "International Spillovers of Monetary Policy: Conventional Policy vs. Quantitative Easing," International Finance Discussion Papers 1234. Board of Governors of the Federal Reserve System.

Dornbusch, Rudiger and Stanley Fischer (1980): "Exchange Rates and the Current Account," American Economic Review 70(5), 960-971.

Eggertsson, Gauti, and Michael Woodford (2003): "The Zero Bound on Interest Rates and Optimal Monetary Policy," Brookings Papers on Economic Activity, vol. 1, 139-211.

Engel, Charles (2014): "Exchange Rates and Interest Parity," Handbook of International Economics vol. 4, 453-522.

Engel, Charles and Kenneth D. West (2015): "Exchange Rates and Fundamentals," Journal of Political Economy 113(3), 485-517.

Engel, Charles (2016): "Exchange Rates, Interest Rates and the Risk Premium," American Economic Review 106(2), 436-474.

Farhi, Emmanuel and Iván Werning (2019): "Monetary Policy, Bounded Rationality and Incomplete Markets," American Economic Review 109(11), 3887-3928.

Gabaix, Xavier (2019): "A Behavioral New Keynesian Model," mimeo.

Galí, Jordi, Mark Gertler, David López-Salido (2005): "Robustness of the Estimates of the Hybrid New Keynesian Phillips Curve," Journal of Monetary Economics, vol. 52, issue 6, 1107-1118. 
Galí, Jordi, and Tommaso Monacelli (2005): "Monetary Policy and Exchange Rate Volatility in a Small Open Economy," Review of Economic Studies, vol. 72, issue 3, 2005, 707-734

Galí, Jordi (2015): Monetary Policy, Inflation and the Business Cycle: An Introduction to the New Keynesian Framework, Second edition, Princeton University Press (Princeton, NJ), chapter 8.

Glick, Reuven and Sylvain Leduc (2018): "Unconventional Monetary Policy and the Dollar: Conventional Signs, Unconventional Magnitudes," International Journal of Central Banking, 103-152.

Del Negro, Marco, Marc P. Giannoni, and Christina Patterson (2015) "The Forward Guidance Puzzle," mimeo.

Jung, Taehun, Yuki Teranishi, and Tsutomo Watanabe, (2005): "Optimal Monetary Policy at the Zero Interest Rate Bound," Journal of Money, Credit and Banking 37 (5), 813-835.

Mavroeides, Sophocles, Mikkel Plagborg-Moller, and James H. Stock (2014): "Empirical Evidence on Inflation Expectations in the New Keynesian Phillips Curve," Journal of Economic Literature 52(1), 124-188.

McKay, Alisdair, Emi Nakamura and Jon Steinsson (2016): "The Power of Forward Guidance Revisited," American Economic Review, 106(10), 3133-3158,

McKay, Alisdair, Emi Nakamura and Jon Steinsson (2017): "The Discounted Euler Equation: A Note," Economica 84, 820-831.

Mussa, Michael (1982): "A Model of Exchange Rate Dynamics," Journal of Political Economy 90(1), 74-104.

Rudd, Jeremy and Karl Whelan (2005): "New Tests of the New Keynesian Phillips Curve," Journal of Monetary Economics, vol. 52, issue 6, 1167-1181.

Werning, Iván (2015): "Incomplete Markets and Aggregate Demand," mimeo.

Wilson, Charles A. (1979): "Anticipated Shocks and Exchange Rate Dynamics," Journal of Political Economy 87(3), 639-647. 


\begin{tabular}{|c|c|c|c|}
\hline \multicolumn{4}{|c|}{ Table 1A } \\
\hline \multicolumn{4}{|c|}{ U.S. - Euro Area Evidence } \\
\hline & 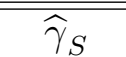 & 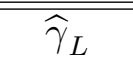 & 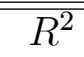 \\
\hline \multicolumn{4}{|l|}{ Baseline } \\
\hline$n=12$ & $\begin{array}{l}2.91^{* *} \\
(0.92)\end{array}$ & $\begin{array}{l}0.36^{* *} \\
(0.05)\end{array}$ & 0.77 \\
\hline$n=24$ & $\begin{array}{l}1.90^{* *} \\
(0.60)\end{array}$ & $\begin{array}{l}0.33^{* *} \\
(0.05)\end{array}$ & 0.77 \\
\hline$n=60$ & $\begin{array}{l}1.27^{* *} \\
(0.31)\end{array}$ & $\frac{0.25^{* *}}{(0.06)}$ & 0.77 \\
\hline$n=120$ & $\begin{array}{l}0.95^{* *} \\
(0.22)\end{array}$ & $\begin{array}{l}0.19^{* *} \\
(0.08)\end{array}$ & 0.75 \\
\hline$n=360$ & $\begin{array}{l}0.41^{* *} \\
(0.04)\end{array}$ & - & 0.50 \\
\hline \multicolumn{4}{|l|}{ Time trend } \\
\hline$n=12$ & $\begin{array}{l}2.76^{* *} \\
(0.85)\end{array}$ & $\begin{array}{l}0.53^{* *} \\
(0.07)\end{array}$ & 0.80 \\
\hline$n=24$ & $\begin{array}{l}1.83^{* *} \\
(0.53)\end{array}$ & $\begin{array}{l}0.50^{* *} \\
(0.08)\end{array}$ & 0.80 \\
\hline$n=60$ & $\begin{array}{l}1.26^{* *} \\
(0.27)\end{array}$ & $\begin{array}{l}0.43^{* *} \\
(0.10)\end{array}$ & 0.80 \\
\hline$n=120$ & $\begin{array}{l}0.94^{* *} \\
(0.20)\end{array}$ & $\begin{array}{l}0.41^{* *} \\
(0.14)\end{array}$ & 0.78 \\
\hline$n=360$ & $\begin{array}{l}0.61^{* *} \\
(0.07)\end{array}$ & - & 0.76 \\
\hline \multicolumn{4}{|l|}{ First differences } \\
\hline$n=12$ & $\begin{array}{l}2.20^{* *} \\
(0.41)\end{array}$ & $\begin{array}{l}0.17^{* *} \\
(0.04)\end{array}$ & 0.18 \\
\hline$n=24$ & $\begin{array}{l}1.07^{* *} \\
(0.48)\end{array}$ & $\begin{array}{l}0.16^{* *} \\
(0.05)\end{array}$ & 0.16 \\
\hline$n=60$ & $\begin{array}{l}0.51^{*} \\
(0.27)\end{array}$ & $\begin{array}{l}0.16^{* *} \\
(0.06)\end{array}$ & 0.14 \\
\hline$n=120$ & $\begin{array}{l}0.41^{* *} \\
(0.13)\end{array}$ & $\begin{array}{l}0.12 \\
(0.05)\end{array}$ & 0.13 \\
\hline$n=360$ & $\begin{array}{l}0.19^{* *} \\
(0.04)\end{array}$ & - & 0.12 \\
\hline
\end{tabular}

Note: The table reports the OLS estimates of $\gamma_{S}$ and $\gamma_{L}$ in the regression equations (17), (21) and (24) in the main text, respectively. Sample period 2004:8-2018:12. Standard errors reported in brackets, computed using the Newey-West adjustment with 12 lags. One and two asterisks indicate significance at 10 and 5 percent level, respectively. 


\begin{tabular}{|c|c|c|c|}
\hline \multicolumn{4}{|c|}{ Table 1B } \\
\hline \multicolumn{4}{|c|}{ U.S.- U.K. Evidence } \\
\hline & 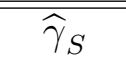 & 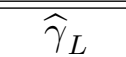 & $R^{2}$ \\
\hline \multicolumn{4}{|l|}{ Baseline } \\
\hline$n=12$ & $\begin{array}{l}4.34^{* *} \\
(0.58)\end{array}$ & $\begin{array}{l}0.23^{* *} \\
(0.06)\end{array}$ & 0.72 \\
\hline$n=24$ & $\begin{array}{l}3.09^{* *} \\
(0.27)\end{array}$ & $\begin{array}{l}0.11^{* *} \\
(0.05)\end{array}$ & 0.77 \\
\hline$n=60$ & $\begin{array}{l}1.85^{* *} \\
(0.21)\end{array}$ & $\begin{array}{c}-0.04 \\
(0.05)\end{array}$ & 0.75 \\
\hline$n=120$ & $\begin{array}{l}1.22^{* *} \\
(0.16)\end{array}$ & $\begin{array}{c}-0.14 \\
(0.08)\end{array}$ & 0.67 \\
\hline$n=360$ & $\begin{array}{l}0.39^{* *} \\
(0.06)\end{array}$ & - & 0.55 \\
\hline \multicolumn{4}{|l|}{ Time trend } \\
\hline$n=12$ & $\begin{array}{l}3.80^{* *} \\
(0.74)\end{array}$ & $\begin{array}{l}0.18^{*} \\
(0.06)\end{array}$ & 0.73 \\
\hline$n=24$ & $\begin{array}{l}3.05^{* *} \\
(0.40)\end{array}$ & $\begin{array}{l}0.13^{* *} \\
(0.05)\end{array}$ & 0.77 \\
\hline$n=60$ & $\begin{array}{l}1.86^{* *} \\
(0.34)\end{array}$ & $\begin{array}{c}-0.04 \\
(0.05)\end{array}$ & 0.75 \\
\hline$n=120$ & $\begin{array}{l}0.93^{* *} \\
(0.25)\end{array}$ & $\begin{array}{l}-0.13^{*} \\
(0.07)\end{array}$ & 0.68 \\
\hline$n=360$ & $\begin{array}{l}0.17^{*} \\
(0.09)\end{array}$ & - & 0.63 \\
\hline \multicolumn{4}{|l|}{ First differences } \\
\hline$n=12$ & $\begin{array}{l}1.45^{* *} \\
(0.56)\end{array}$ & $\begin{array}{l}0.00 \\
(0.04)\end{array}$ & 0.04 \\
\hline$n=24$ & $\begin{array}{l}1.13^{* *} \\
(0.25)\end{array}$ & $\begin{array}{c}-0.02 \\
(0.05)\end{array}$ & 0.07 \\
\hline$n=60$ & $\begin{array}{l}0.55^{* *} \\
(0.19)\end{array}$ & $\begin{array}{c}-0.04 \\
(0.04)\end{array}$ & 0.05 \\
\hline$n=120$ & $\begin{array}{l}0.28^{* *} \\
(0.14)\end{array}$ & $\begin{array}{c}-0.07 \\
(0.05)\end{array}$ & 0.03 \\
\hline$n=360$ & $\begin{array}{l}0.01 \\
(0.05)\end{array}$ & - & 0.01 \\
\hline
\end{tabular}

Note: The table reports the OLS estimates of $\gamma_{S}$ and $\gamma_{L}$ in the regression equations (17), (21) and (24) in the main text, respectively. Sample period 2004:8-2018:12. Standard errors reported in brackets, computed using the Newey-West adjustment with 12 lags. One and two asterisks indicate significance at 10 and 5 percent level, respectively. 


\begin{tabular}{|c|c|c|c|}
\hline \multicolumn{4}{|c|}{$\begin{array}{c}\text { Table } 1 \mathrm{C} \\
\end{array}$} \\
\hline \multicolumn{4}{|c|}{ Euro Area - U.K. Evidence } \\
\hline & 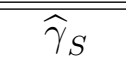 & 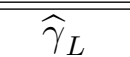 & 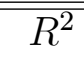 \\
\hline \multicolumn{4}{|l|}{ Baseline } \\
\hline$n=12$ & $\begin{array}{l}3.91^{* *} \\
(0.92)\end{array}$ & $\begin{array}{l}0.30^{* *} \\
(0.10)\end{array}$ & 0.41 \\
\hline$n=24$ & $\begin{array}{l}2.51^{* *} \\
(0.46)\end{array}$ & $\begin{array}{l}0.30^{* *} \\
(0.09)\end{array}$ & 0.44 \\
\hline$n=60$ & $\begin{array}{l}1.57^{* *} \\
(0.28)\end{array}$ & $\begin{array}{l}0.25^{* *} \\
(0.10)\end{array}$ & 0.44 \\
\hline$n=120$ & $\begin{array}{l}1.21^{* *} \\
(0.20)\end{array}$ & $\begin{array}{l}0.14 \\
(0.11)\end{array}$ & 0.40 \\
\hline$n=360$ & $\begin{array}{l}0.30 \\
(0.11)\end{array}$ & - & 0.15 \\
\hline \multicolumn{4}{|l|}{ Time trend } \\
\hline$n=12$ & $\begin{array}{l}4.02^{* *} \\
(1.09)\end{array}$ & $\begin{array}{l}0.30^{* *} \\
(0.09)\end{array}$ & 0.41 \\
\hline$n=24$ & $\begin{array}{l}2.92^{* *} \\
(0.62)\end{array}$ & $\begin{array}{l}0.30^{* *} \\
(0.09)\end{array}$ & 0.45 \\
\hline$n=60$ & $\begin{array}{l}2.10^{* *} \\
(0.43)\end{array}$ & $\begin{array}{l}0.24^{* *} \\
(0.09)\end{array}$ & 0.47 \\
\hline$n=120$ & $\begin{array}{l}1.68^{* *} \\
(0.31)\end{array}$ & $\begin{array}{l}0.05 \\
(0.10)\end{array}$ & 0.44 \\
\hline$n=360$ & $\begin{array}{l}0.30 \\
(0.10)\end{array}$ & - & 0.24 \\
\hline \multicolumn{4}{|l|}{ First differences } \\
\hline$n=12$ & $\begin{array}{l}0.42 \\
(0.66)\end{array}$ & $\begin{array}{l}0.16^{* *} \\
(0.03)\end{array}$ & 0.10 \\
\hline$n=24$ & $\begin{array}{l}0.53^{* *} \\
(0.11)\end{array}$ & $\begin{array}{l}0.15^{* *} \\
(0.03)\end{array}$ & 0.11 \\
\hline$n=60$ & $\begin{array}{l}0.38 \\
(0.31)\end{array}$ & $\begin{array}{l}0.15 \\
(0.04)\end{array}$ & 0.11 \\
\hline$n=120$ & $\begin{array}{l}0.14 \\
(0.21)\end{array}$ & $\begin{array}{l}0.17^{* *} \\
(0.06)\end{array}$ & 0.10 \\
\hline$n=360$ & $\begin{array}{l}0.16 \\
(0.02)\end{array}$ & - & 0.10 \\
\hline
\end{tabular}

Note: The table reports the OLS estimates of $\gamma_{S}$ and $\gamma_{L}$ in the regression equations (17), (21) and (24) in the main text, respectively. Sample period 2004:8-2018:12. Standard errors reported in brackets, computed using the Newey-West adjustment with 12 lags. One and two asterisks indicate significance at 10 and 5 percent level, respectively. 


\begin{tabular}{|c|c|c|c|}
\hline \multicolumn{4}{|c|}{$\begin{array}{ll}\text { Table 2A } \\
\end{array}$} \\
\hline \multicolumn{4}{|c|}{ U.S.-Euro Area Evidence: Term Premium Adjustment } \\
\hline & $\widehat{\gamma}_{S}$ & $\widehat{\gamma}_{L}$ & $R^{2}$ \\
\hline \multicolumn{4}{|l|}{ Baseline } \\
\hline$n=12$ & $\begin{array}{l}1.77^{* *} \\
(0.78)\end{array}$ & $\begin{array}{l}0.37^{* *} \\
(0.04)\end{array}$ & 0.80 \\
\hline$n=24$ & $\begin{array}{l}1.12^{* *} \\
(0.48)\end{array}$ & $\begin{array}{l}0.36^{* *} \\
(0.05)\end{array}$ & 0.79 \\
\hline$n=60$ & $\begin{array}{l}0.86^{* *} \\
(0.28)\end{array}$ & $\begin{array}{l}0.33^{* *} \\
(0.06)\end{array}$ & 0.80 \\
\hline$n=120$ & $\begin{array}{l}0.78^{* *} \\
(0.20)\end{array}$ & $\begin{array}{l}0.27^{* *} \\
(0.07)\end{array}$ & 0.75 \\
\hline$n=360$ & $\begin{array}{l}0.41^{* *} \\
(0.03)\end{array}$ & - & 0.78 \\
\hline \multicolumn{4}{|l|}{ Time trend } \\
\hline$n=12$ & $\begin{array}{l}1.37^{* *} \\
(0.67)\end{array}$ & $\begin{array}{l}0.51^{* *} \\
(0.05)\end{array}$ & 0.83 \\
\hline$n=24$ & $\begin{array}{l}0.91^{* *} \\
(0.39)\end{array}$ & $\begin{array}{l}0.51^{* *} \\
(0.06)\end{array}$ & 0.82 \\
\hline$n=60$ & $\begin{array}{l}0.75^{* *} \\
(0.22)\end{array}$ & $\begin{array}{l}0.49^{* *} \\
(0.08)\end{array}$ & 0.82 \\
\hline$n=120$ & $\begin{array}{l}0.71^{* *} \\
(0.16)\end{array}$ & $\begin{array}{l}0.06^{* *} \\
(0.02)\end{array}$ & 0.82 \\
\hline$n=360$ & $\begin{array}{l}0.55^{* *} \\
(0.03)\end{array}$ & - & 0.82 \\
\hline \multicolumn{4}{|l|}{ First differences } \\
\hline$n=12$ & $\begin{array}{l}1.65^{* *} \\
(0.40)\end{array}$ & $\begin{array}{l}0.11 \\
(0.08)\end{array}$ & 0.11 \\
\hline$n=24$ & $\begin{array}{l}0.77 \\
(0.43)\end{array}$ & $\begin{array}{l}0.11 \\
(0.07)\end{array}$ & 0.09 \\
\hline$n=60$ & $\begin{array}{l}0.39 \\
(0.27)\end{array}$ & $\begin{array}{l}0.11 \\
(0.07)\end{array}$ & 0.08 \\
\hline$n=120$ & $\begin{array}{l}0.36^{* *} \\
(0.17)\end{array}$ & $\begin{array}{l}0.09 \\
(0.07)\end{array}$ & 0.08 \\
\hline$n=360$ & $\begin{array}{l}0.14 \\
(0.08)\end{array}$ & - & 0.07 \\
\hline
\end{tabular}

Note: The table reports the OLS estimates of $\gamma_{S}$ and $\gamma_{L}$ in the regression equations (17), (21) and (24) in the main text, respectively. Sample period 2004:8-2018:12. Standard errors reported in brackets, computed using the Newey-West adjustment with 12 lags. One and two asterisks indicate significance at 10 and 5 percent level, respectively. 


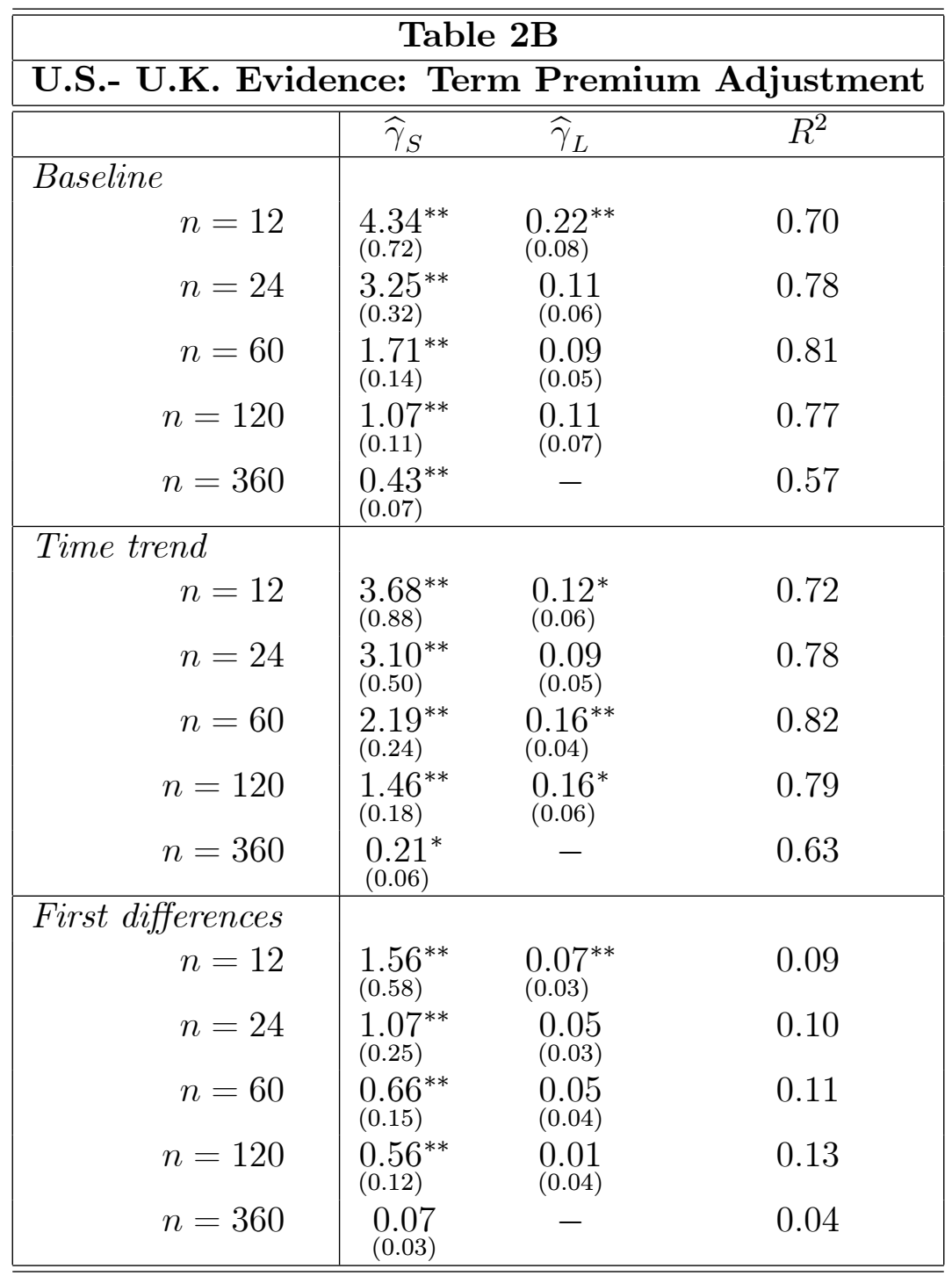

Note: The table reports the OLS estimates of $\gamma_{S}$ and $\gamma_{L}$ in the regression equations (17), (21) and (24) in the main text, respectively. Sample period 2004:8-2018:12. Standard errors reported in brackets, computed using the Newey-West adjustment with 12 lags. One and two asterisks indicate significance at 10 and 5 percent level, respectively. 


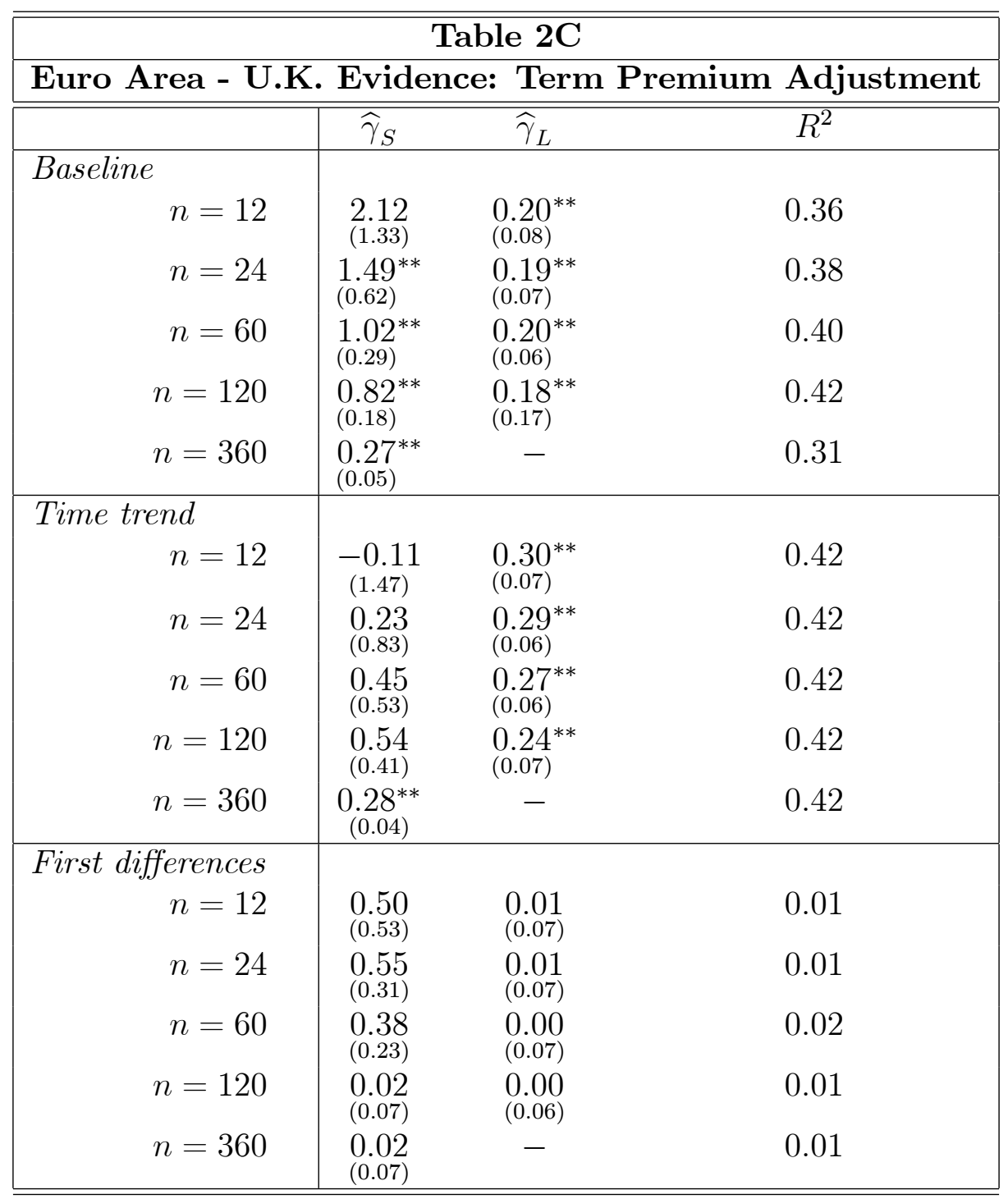

Note: The table reports the OLS estimates of $\gamma_{S}$ and $\gamma_{L}$ in the regression equations (17), (21) and (24) in the main text, respectively. Sample period 2004:8-2018:12. Standard errors reported in brackets, computed using the Newey-West adjustment with 12 lags. One and two asterisks indicate significance at 10 and 5 percent level, respectively. 


\begin{tabular}{|c|c|c|c|}
\hline \multicolumn{4}{|c|}{ Table 3A } \\
\hline \multicolumn{4}{|c|}{ U.S.-Euro Area Evidence: Nominal Specification } \\
\hline & 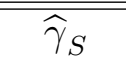 & 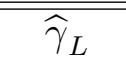 & $\bar{c}^{2}$ \\
\hline \multicolumn{4}{|l|}{ Baseline } \\
\hline$n=12$ & $\begin{array}{l}2.61^{* *} \\
(1.09)\end{array}$ & $\begin{array}{l}0.33^{* *} \\
(0.09)\end{array}$ & 0.72 \\
\hline$n=24$ & $\begin{array}{l}1.74^{* *} \\
(0.58)\end{array}$ & $\begin{array}{l}0.29^{* *} \\
(0.09)\end{array}$ & 0.73 \\
\hline$n=60$ & $\begin{array}{l}0.87^{* *} \\
(0.24)\end{array}$ & $\begin{array}{l}0.21^{* *} \\
(0.05)\end{array}$ & 0.79 \\
\hline$n=120$ & $\begin{array}{l}0.58^{* *} \\
(0.18)\end{array}$ & $\begin{array}{l}0.24^{* *} \\
(0.07)\end{array}$ & 0.75 \\
\hline$n=360$ & $\begin{array}{l}0.43^{* *} \\
(0.05)\end{array}$ & - & 0.68 \\
\hline \multicolumn{4}{|l|}{ Time trend } \\
\hline$n=12$ & $\begin{array}{l}2.80^{* *} \\
(1.33)\end{array}$ & $\begin{array}{l}0.29^{* *} \\
(0.14)\end{array}$ & 0.72 \\
\hline$n=24$ & $\begin{array}{l}1.82^{* *} \\
(0.68)\end{array}$ & $\begin{array}{l}0.25^{* *} \\
(0.14)\end{array}$ & 0.73 \\
\hline$n=60$ & $\begin{array}{l}0.74^{* *} \\
(0.17)\end{array}$ & $\begin{array}{l}0.41^{* *} \\
(0.06)\end{array}$ & 0.83 \\
\hline$n=120$ & $\begin{array}{l}0.52^{* *} \\
(0.14)\end{array}$ & $\begin{array}{l}0.07^{* *} \\
(0.02)\end{array}$ & 0.81 \\
\hline$n=360$ & $\begin{array}{l}0.46^{* *} \\
(0.08)\end{array}$ & - & 0.69 \\
\hline \multicolumn{4}{|l|}{ First differences } \\
\hline$n=12$ & $\begin{array}{l}6.28^{* *} \\
(1.43)\end{array}$ & $\begin{array}{l}0.12^{* *} \\
(0.04)\end{array}$ & 0.27 \\
\hline$n=24$ & $\begin{array}{l}3.10^{* *} \\
(0.65)\end{array}$ & $\begin{array}{l}0.11^{*} \\
(0.06)\end{array}$ & 0.27 \\
\hline$n=60$ & $\begin{array}{l}1.17^{* *} \\
(0.30)\end{array}$ & $\begin{array}{l}0.13^{* *} \\
(0.06)\end{array}$ & 0.26 \\
\hline$n=120$ & $\begin{array}{l}0.54^{* *} \\
(0.18)\end{array}$ & $\begin{array}{l}0.13^{* *} \\
(0.05)\end{array}$ & 0.18 \\
\hline$n=360$ & $\begin{array}{l}0.20^{* *} \\
(0.06)\end{array}$ & - & 0.14 \\
\hline
\end{tabular}

Note: The table reports the OLS estimates of $\gamma_{S}$ and $\gamma_{L}$ in the regression equations (17), (21) and (24) in the main text, respectively. Sample period 2004:8-2018:12. Standard errors reported in brackets, computed using the Newey-West adjustment with 12 lags. One and two asterisks indicate significance at 10 and 5 percent level, respectively. 


\begin{tabular}{|c|c|c|c|}
\hline \multicolumn{4}{|c|}{$\begin{array}{l}\text { Table 3B } \\
\end{array}$} \\
\hline \multicolumn{4}{|c|}{ U.S.- U.K. Evidence: Nominal Specification } \\
\hline & $\widehat{\gamma}_{S}$ & $\widehat{\gamma}_{L}$ & $R^{2}$ \\
\hline \multicolumn{4}{|l|}{ Baseline } \\
\hline$n=12$ & $\begin{array}{l}9.41^{* *} \\
(1.33)\end{array}$ & $\begin{array}{c}-0.06 \\
(0.12)\end{array}$ & 0.56 \\
\hline$n=24$ & $\begin{array}{l}5.17^{* *} \\
(0.76)\end{array}$ & $\begin{array}{l}-0.13 \\
(0.13)\end{array}$ & 0.62 \\
\hline$n=60$ & $\begin{array}{l}2.09^{* *} \\
(0.32)\end{array}$ & $\begin{array}{l}0.00 \\
(0.09)\end{array}$ & 0.59 \\
\hline$n=120$ & $\begin{array}{l}0.98^{* *} \\
(0.30)\end{array}$ & $\begin{array}{l}0.12 \\
(0.13)\end{array}$ & 0.46 \\
\hline$n=360$ & $\begin{array}{l}0.29^{*} \\
(0.16)\end{array}$ & - & 0.16 \\
\hline \multicolumn{4}{|l|}{ Time trend } \\
\hline$n=12$ & $\begin{array}{l}5.33^{* *} \\
(1.42)\end{array}$ & $\begin{array}{c}-0.07 \\
(0.12)\end{array}$ & 0.69 \\
\hline$n=24$ & $\begin{array}{l}3.15^{* *} \\
(0.70)\end{array}$ & $\begin{array}{l}-0.10 \\
(0.12)\end{array}$ & 0.71 \\
\hline$n=60$ & $\begin{array}{l}1.25^{* *} \\
(0.28)\end{array}$ & $\begin{array}{c}-0.04 \\
(0.09)\end{array}$ & 0.68 \\
\hline$n=120$ & $\begin{array}{l}0.34 \\
(0.24)\end{array}$ & $\begin{array}{l}0.04 \\
(0.11)\end{array}$ & 0.63 \\
\hline$n=360$ & $\begin{array}{l}0.21^{*} \\
(0.06)\end{array}$ & - & 0.61 \\
\hline \multicolumn{4}{|l|}{ First differences } \\
\hline$n=12$ & $\begin{array}{l}3.98^{* *} \\
(1.33)\end{array}$ & $\begin{array}{l}-0.08 \\
(0.03)\end{array}$ & 0.08 \\
\hline$n=24$ & $\begin{array}{l}2.75^{* *} \\
(0.74)\end{array}$ & $\begin{array}{l}-0.13 \\
(0.04)\end{array}$ & 0.14 \\
\hline$n=60$ & $\begin{array}{l}0.86^{* *} \\
(0.29)\end{array}$ & $\begin{array}{c}-0.07 \\
(0.05)\end{array}$ & 0.17 \\
\hline$n=120$ & $\begin{array}{l}0.23 \\
(0.16)\end{array}$ & $\begin{array}{l}-0.05 \\
(0.05)\end{array}$ & 0.01 \\
\hline$n=360$ & $\begin{array}{l}-0.06 \\
(0.04)\end{array}$ & - & 0.01 \\
\hline
\end{tabular}

Note: The table reports the OLS estimates of $\gamma_{S}$ and $\gamma_{L}$ in the regression equations (17), (21) and (24) in the main text, respectively. Sample period 2004:8-2018:12. Standard errors reported in brackets, computed using the Newey-West adjustment with 12 lags. One and two asterisks indicate significance at 10 and 5 percent level, respectively. 


\begin{tabular}{|c|c|c|c|}
\hline \multicolumn{4}{|c|}{$\begin{array}{ll}\text { Table } 3 \mathrm{C} \\
\end{array}$} \\
\hline \multicolumn{4}{|c|}{ Euro Area - U.K. Evidence: Nominal Specification } \\
\hline & 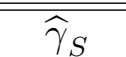 & $\widehat{C}_{L}$ & 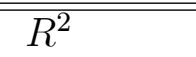 \\
\hline \multicolumn{4}{|l|}{ Baseline } \\
\hline$n=12$ & $\begin{array}{l}8.84^{* *} \\
(1.48)\end{array}$ & $\begin{array}{l}0.11 \\
(0.10)\end{array}$ & 0.50 \\
\hline$n=24$ & $\begin{array}{l}4.92^{* *} \\
(0.88)\end{array}$ & $\begin{array}{l}0.08 \\
(0.09)\end{array}$ & 0.51 \\
\hline$n=60$ & $\begin{array}{l}2.49^{* *} \\
(0.45)\end{array}$ & $\frac{-0.01}{(0.11)}$ & 0.48 \\
\hline$n=120$ & $\begin{array}{l}1.38^{* *} \\
(0.42)\end{array}$ & $\begin{array}{l}-0.19 \\
(0.15)\end{array}$ & 0.30 \\
\hline$n=360$ & $\begin{array}{c}-0.00 \\
(0.14)\end{array}$ & - & 0.01 \\
\hline \multicolumn{4}{|l|}{ Time trend } \\
\hline$n=12$ & $\begin{array}{l}8.67^{* *} \\
(1.68)\end{array}$ & $\begin{array}{l}0.28^{* *} \\
(0.11)\end{array}$ & 0.60 \\
\hline$n=24$ & $\begin{array}{l}4.99^{* *} \\
(0.93)\end{array}$ & $\begin{array}{l}0.27^{* *} \\
(0.10)\end{array}$ & 0.63 \\
\hline$n=60$ & $\begin{array}{l}2.72^{* *} \\
(0.48)\end{array}$ & $\begin{array}{l}0.10 \\
(0.08)\end{array}$ & 0.60 \\
\hline$n=120$ & $\begin{array}{l}1.78^{* *} \\
(0.41)\end{array}$ & $\begin{array}{l}-0.04 \\
(0.12)\end{array}$ & 0.49 \\
\hline$n=360$ & $\begin{array}{l}0.20^{*} \\
(0.12)\end{array}$ & - & 0.15 \\
\hline \multicolumn{4}{|l|}{ First differences } \\
\hline$n=12$ & $\begin{array}{l}7.18^{* *} \\
(1.53)\end{array}$ & $\begin{array}{l}0.09^{* *} \\
(0.02)\end{array}$ & 0.33 \\
\hline$n=24$ & $\begin{array}{l}3.38^{* *} \\
(0.87)\end{array}$ & $\begin{array}{l}0.10^{* *} \\
(0.03)\end{array}$ & 0.29 \\
\hline$n=60$ & $\begin{array}{l}1.35^{* *} \\
(0.23)\end{array}$ & $\begin{array}{l}0.11^{* *} \\
(0.05)\end{array}$ & 0.29 \\
\hline$n=120$ & $\begin{array}{l}0.69^{* *} \\
(0.23)\end{array}$ & $\begin{array}{l}0.08^{*} \\
(0.04)\end{array}$ & 0.23 \\
\hline$n=360$ & $\begin{array}{l}0.15^{* *} \\
(0.04)\end{array}$ & - & 0.13 \\
\hline
\end{tabular}

Note: The table reports the OLS estimates of $\gamma_{S}$ and $\gamma_{L}$ in the regression equations (17), (21) and (24) in the main text, respectively. Sample period 2004:8-2018:12. Standard errors reported in brackets, computed using the Newey-West adjustment with 12 lags. One and two asterisks indicate significance at 10 and 5 percent level, respectively. 


\begin{tabular}{|c|lc|}
\hline \hline \multicolumn{3}{|c|}{ Table 4 } \\
\hline \multicolumn{3}{|c|}{ Behavioral Model: Implied Coefficients } \\
\hline \hline U.S.-Euro Area & $\gamma_{S}$ & $\gamma_{L}$ \\
$n=12$ & 2.70 & 0.43 \\
$n=24$ & 1.75 & 0.39 \\
$n=60$ & 1.19 & 0.26 \\
$n=120$ & 1.01 & -0.07 \\
& & \\
\hline U.S.-U.K & & \\
$n=12$ & 4.21 & 0.33 \\
$n=24$ & 2.60 & 0.28 \\
$n=60$ & 1.64 & 0.06 \\
$n=120$ & 1.34 & -0.52 \\
& & \\
$n=12$ & 3.28 & 0.52 \\
$n=24$ & 2.13 & 0.48 \\
$n=60$ & 1.45 & 0.32 \\
$n=120$ & 1.23 & -0.09 \\
& & \\
\hline \hline
\end{tabular}

Note: The table reports the values for $\gamma_{S}(n)$ and $\gamma_{L}(n)$ at different horizons based on the settings for $\left(\rho_{u}, \rho_{v}, \alpha, \varkappa\right)$ that minimize the distance with the corresponding OLS estimates from the baseline specification in Tables 1A-1C. 


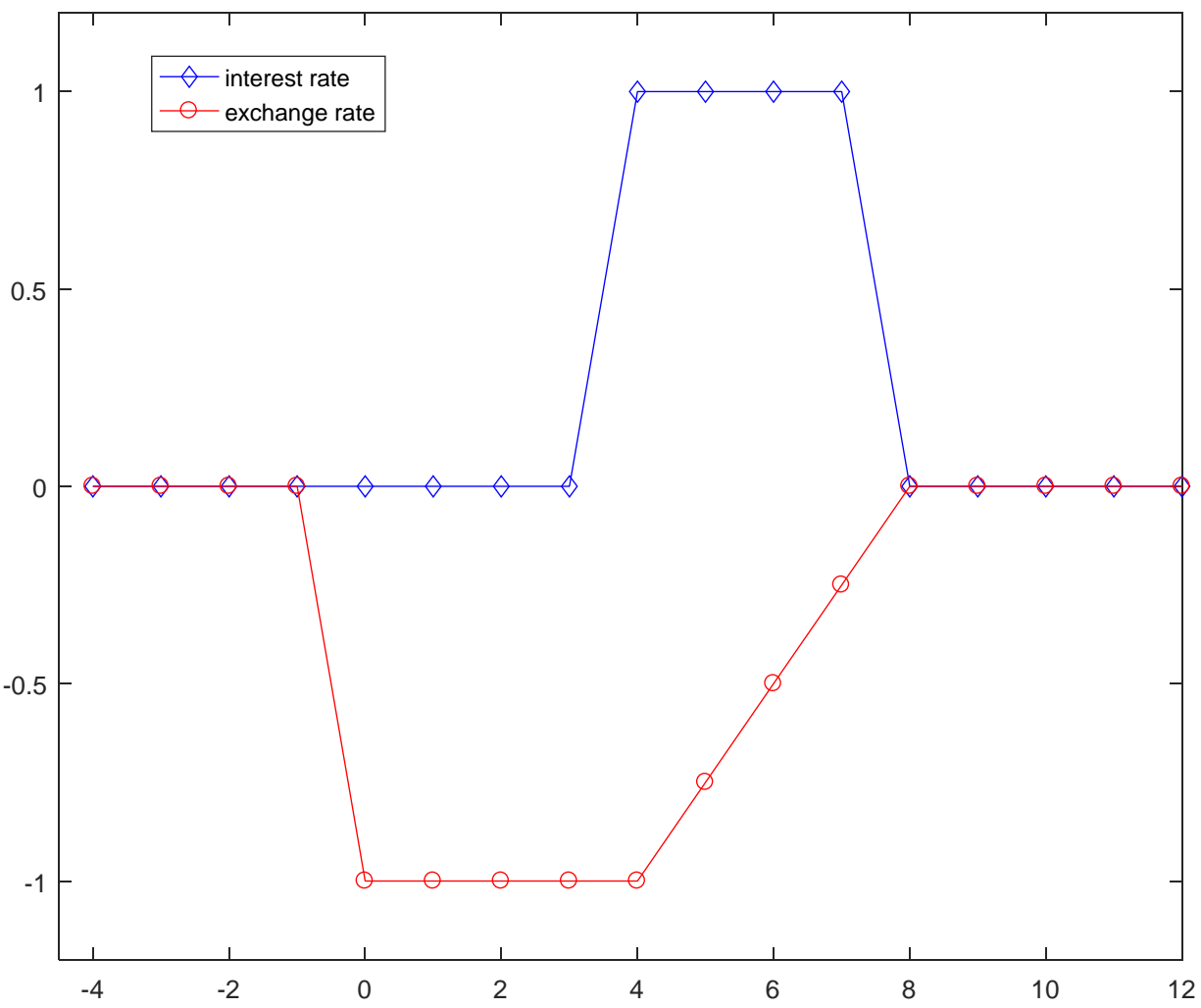

Figure 1. Forward Guidance and the Exchange Rate:

Partial Equilibrium 

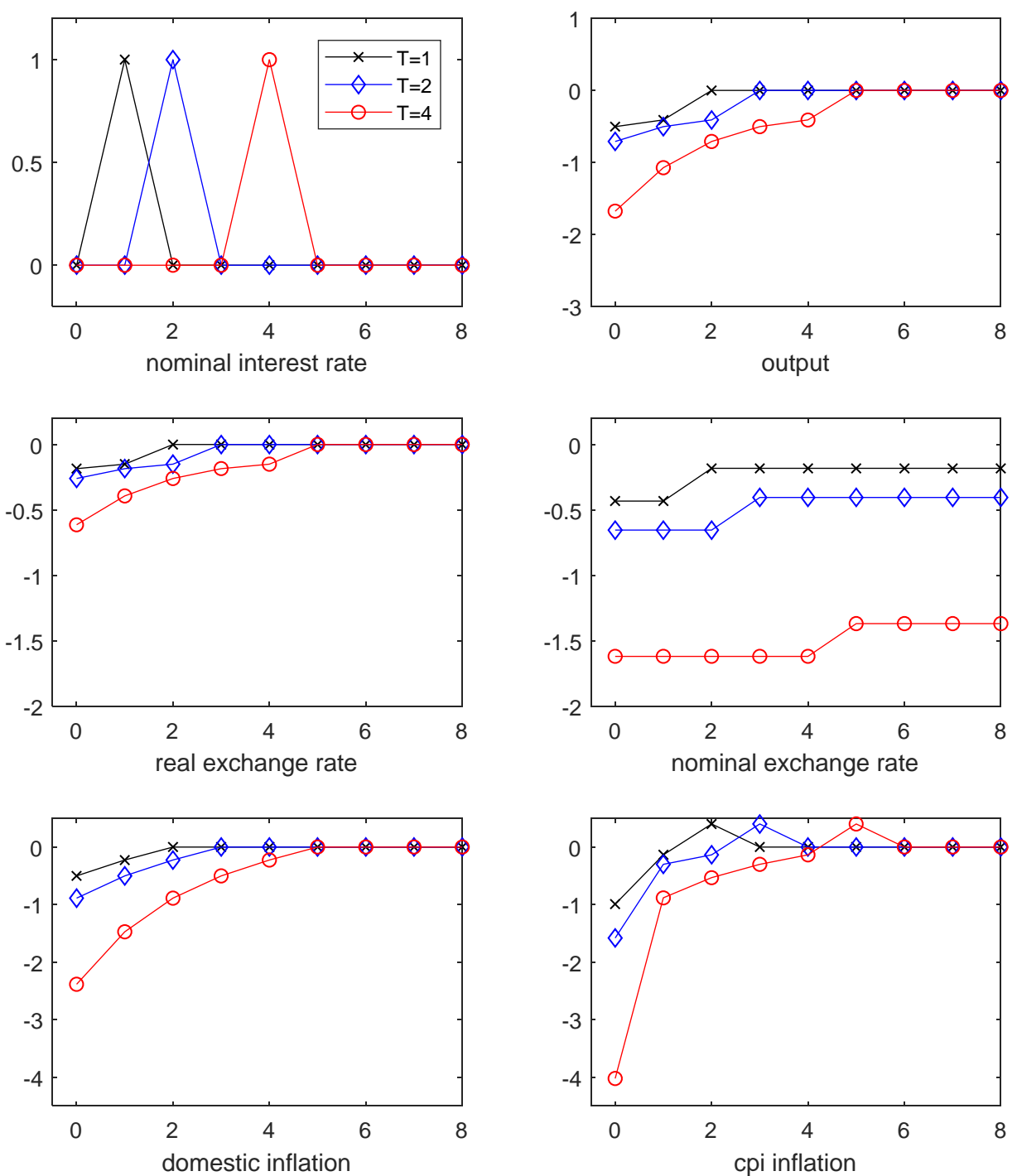

Figure 2. Forward Guidance in the Open Economy: The Role of the Horizon 


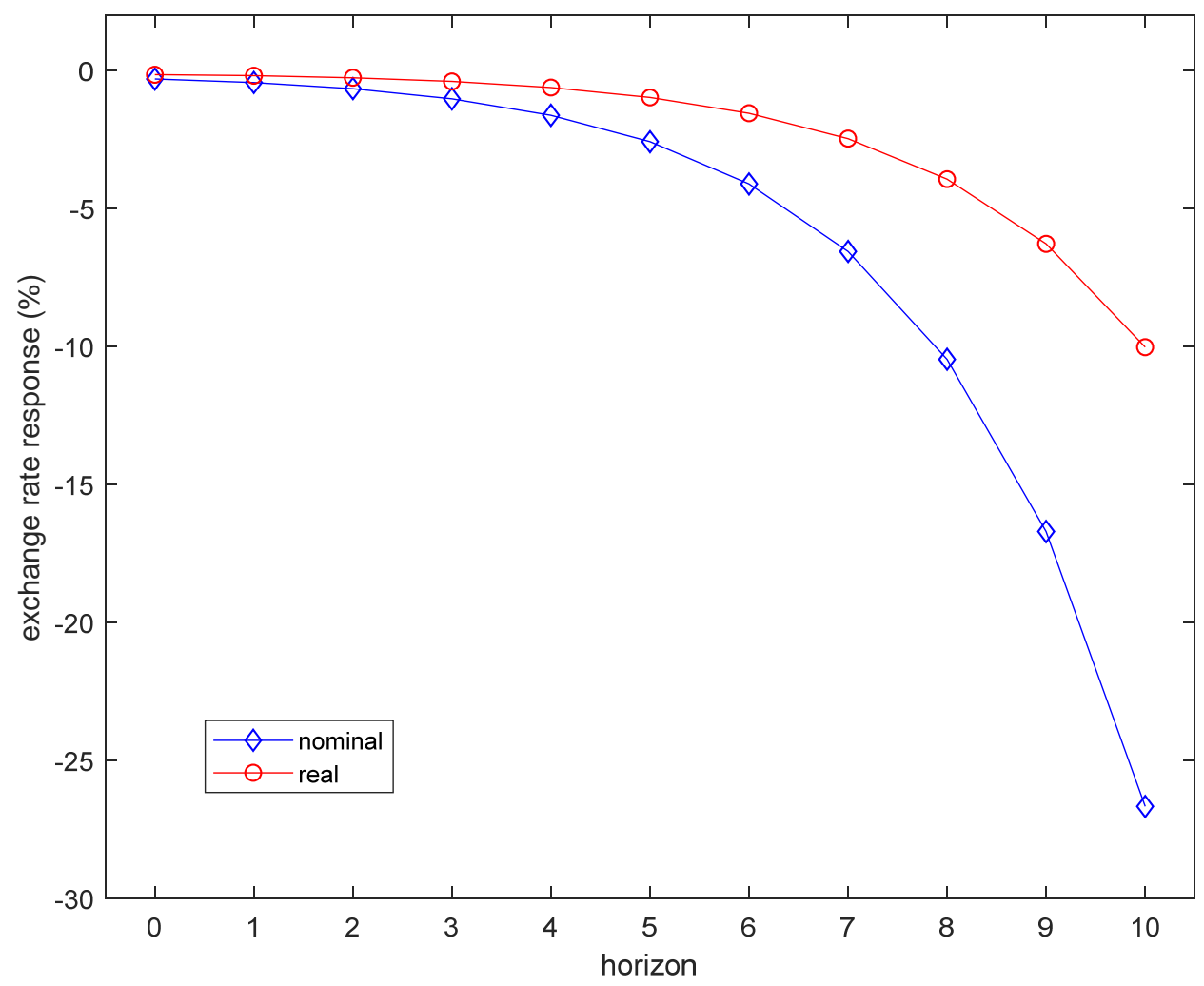

Figure 3. Forward Guidance: Exchange Rate Response and Implementation Horizon 